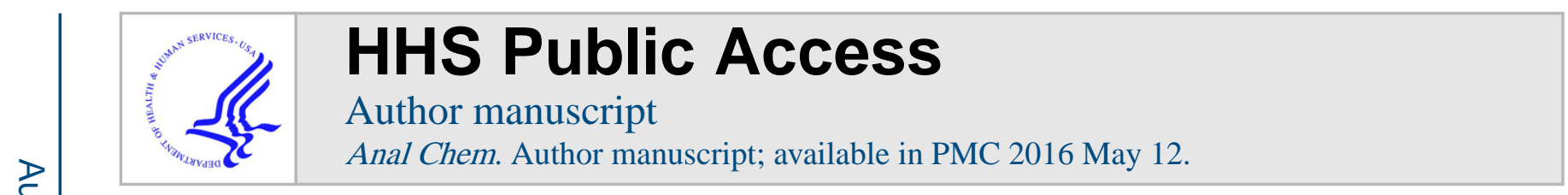

Published in final edited form as:

Anal Chem. 2016 January 5; 88(1): 339-353. doi:10.1021/acs.analchem.5b04139.

\title{
Discovery in Droplets
}

\author{
Alexander K. Price and Brian M. Paegel ${ }^{\star}$ \\ Department of Chemistry, The Scripps Research Institute, Jupiter, FL 33458, United States
}

\section{INTRODUCTION}

In the summer of 2009, Daniel Chiu's prescient review in Analytical Chemistry described droplet microfluidics, an emerging concept and malleable analytical tool. ${ }^{1}$ The article primarily discussed the potential of single droplets to aid in the study of immensely complex systems, such as single cells and organelles. But droplets, by way of miniaturization and parallelization, were also clearly poised to survey much broader swathes of chemical and biological space in discovery-oriented high-throughput experimentation. Picoliter-scale analysis coupled with microfluidic integration could very realistically deliver million-fold improvements in throughput, potentially revolutionizing diverse applications from protein engineering to drug lead identification. The technology needed to tackle these difficult problems was still just emerging, but 2009 featured a dramatic expansion in microfluidic componentry for generating and manipulating large quantities of droplets (e.g., incubation, picoinjection, sorting, etc.). Today they collectively form the microfluidic circuit engineer's standard palette of parts. Microfluidic circuit component integration, once largely concerned with moving bulk fluid between reactions and separation-based analysis channels, has entered a digital renaissance. Single devices now generate, handle, and analyze sample collections that vastly eclipse the capabilities of even the most sophisticated robotic automation. This review highlights recent (primarily 2013-2015) themes in technology development that continue to build the foundation of droplet-based discovery platforms, and new challenges in droplet-scale information storage and retrieval that have coalesced around these new platforms.

\section{THE FRONT-END OF DISCOVERY: MORE, FASTER}

Microplate-based high-throughput screening (HTS) has fueled the past six decades of biomedical discovery. In practice, plate-based library diversity plateaus around $\sim 10^{6}$ members because a library of 1 million anything residing in 1,536-well plates requires 652 stock plates. Each library screen requires an additional 652 assay plates. The collective curation and manipulation of these libraries is impossible without highly sophisticated robotic automation, and even then, screens require weeks to execute and prodigious amounts of reagent $(>10 \mathrm{~L})$. Increasing the throughput of fluid handling and miniaturizing assay volume might permit access to modestly larger libraries, but the infrastructure that underpins plate-based libraries has essentially exhausted its modularity and scalability. Moore's Law

\footnotetext{
*Corresponding Author: briandna@ scripps.edu.
}

The authors declare no competing financial interests. 
does not apply to microplates, and so libraries of 10 million or more members require a new screening paradigm.

\section{Droplet generation}

Microfluidic droplet-based assays are typically performed at $\mathrm{pL}$ - to $\mathrm{nL}$-scale. Decreasing droplet size is highly desirable for many applications. Maintaining throughput increases droplet yield for the same amount of reagent and time, which in turn allows access to higher library diversity. Producing smaller droplets using a standard flow-focusing junction typically entails an investigation of nozzle width, shear force, or interfacial tension. Producing large shear forces at the junction requires large flow rates, which can cause device delamination. However, employing a dual-layer PDMS circuit with shallow channels only at the generation junction (10- $\mu \mathrm{m}$-wide nozzle) reduced the back pressure and allowed verifiable generation of $\sim 10-50-\mathrm{fL}$ droplets at ultra-high frequency $(200 \mathrm{kHz}-1.3 \mathrm{Mhz}){ }^{2}$ This methodology extends to flow conditions that yield $\sim$-fL droplets at $9.8 \mathrm{MHz}$, but the rate was too fast to measure using a confocal microscopy system. Unlike femtoliter-scale droplets of bulk emulsification, microfluidic droplets produced in this manner are monodisperse $(\mathrm{CV}=2 \%)$.

Microfluidic step emulsification (MSE) is another reliable route to femtoliter-scale droplets. The continuous phase stably confines the dispersed phase in a shallow "Hele-Shaw" channel that opens abruptly into a wide, deep channel. The transition between these two channels causes the disperse stream to break into droplets with sizes dependent on the Hele-Shaw channel depth and width. ${ }^{3}$ MSE produces highly monodisperse droplets $(\mathrm{CV}<2 \%)$ at rates up to $11 \mathrm{kHz} .{ }^{4}$ Of course, femtoliter-scale droplet generation may not be useful in applications lacking complementary tools for high-throughput droplet manipulation, but a wide range of droplet processes (e.g., droplet mixing, dielectrophoretic sorting, paired electrocoalescence, passive droplet splitting, off-chip incubation, reinjection) that already function robustly in the regime of pico- and nanoliter droplets also scale to femtoliter droplets. ${ }^{4}$ Importantly, device fabrication using standard soft lithography maintains accessibility for the broader microfluidics community.

Parallel droplet generation provides an alternative (but complementary) strategy for increasing throughput. Parallelization reduces back pressure and thereby risk of catastrophic delamination by dividing the back pressure amongst multiple identical circuits or circuit pathways. ${ }^{5-7}$ While patterning parallel circuitry on a single device is trivial, additional syringe pumps, tubing manifolds, and other practical considerations can complicate device operation. This is especially true for multiplexed analyses that require emulsions with multiple, distinct dispersed phases, such as the system of Lim et al., ${ }^{8}$ featuring 10 parallel, individually-addressable flow-focusing droplet generators. Large, open wells are filled by pipette with aqueous and the entire device is placed inside a closed chamber that is subsequently pressurized, driving dispersed phase through the circuit while oil flow is controlled by a syringe pump external to the chamber. The system reproducibly generated picoliter-scale droplets using all 10 nozzles with high total frequency $(\sim 4-110 \mathrm{kHz})$. Since each additional nozzle requires no additional equipment, circuit packing is the primary factor that limits throughput. 
Another parallelization strategy uses a combination of aligned "hard" and "soft" master molds to create a three-dimensional channel manifold within a single PDMS slab. ${ }^{9}$ The circuit (Figure 1) consists of 20 rows that each harbor 50 flow-focusing droplet generators, for 1,000 total nozzles supplied by one aqueous input, one oil input, and dispensing into one output. This monolithic elastomer device (3D MED) reproducibly generates picoliter-scale droplets at rates up to $8.7 \mathrm{MHz}$, which is the highest reported frequency to date.

Some microchannel geometries are more amenable to parallelization than others. Parallelization of the T-junction geometry ${ }^{10}$ is straightforward: multiple droplet nozzles intersect a common oil-shearing channel. Step emulsification is also amenable to parallelization, with 37 nozzles generating at a total frequency of $\sim 10 \mathrm{kHz} .{ }^{4}$ Alternatively, combining several of the aforementioned approaches could lead to massive gains in droplet generation throughput. ${ }^{2,8}$

\section{Droplet detection \& sorting}

Droplet detection divides into two general application-specific paradigms: enrich the "winner" or "hit" pool for a subsequent (post-)processing step (e.g., a further round of mutagenesis in directed evolution) or simply detect activity. The latter category allows for batch detection of droplets, which is particularly useful for diagnostic applications where a species of interest can be quantified by limiting dilution prior to encapsulation, i.e. droplets either contain 1 or no elements. The sensitivity of such a digital measurement is dependent simply upon the volumetric throughput. Recently, integration of microfluidic systems and a wide-field photolithographic microlens array enabled droplet detection at $2 \mathrm{kHz}$ per microlens using a high-speed camera. ${ }^{11}$ The device, which features a reflective channel surface to direct emitted light for collection, is capable of measuring [fluorescein] $=2.5 \mu \mathrm{M}$.

Since high-speed cameras are prohibitively expensive for many research labs, one workaround entails bonding a microfluidic circuit with 16 parallel channels directly to the glass cover plate of a CMOS sensor. ${ }^{12}$ The maximum acquisition rate of the sensor, which can be upgraded over time with faster sensors, could detect 40-pL droplets at $254 \mathrm{kHz}$. The system accurately measured "hit" droplet concentration from 1 per million to 1 per hundred; beyond this, the presence of multiple adjacent fluorescent droplets obscures the measurement due to the 2 -fold variance in droplet velocity in the detection region.

Poor sensitivity is typically the trade-off for high throughput, especially when using LEDs to excite droplets over a large field of view. Integrated Comprehensive Droplet Digital Detection (IC 3D) interrogates droplets in a glass cuvette with vertical and rotational translation using a confocal laser microscopy setup. ${ }^{13,14}$ Despite the absence of flow, the system detects fluorescent droplets at $50-200 \mathrm{kHz}$ up to a total aqueous volume of $1 \mathrm{~mL}$. This increases the sensitivity of digital measurements, accurately detecting 1 "hit" droplet per 40 million at $\sim 77 \%$ confidence. Laser-induced fluorescence extends detection down to at least $250 \mathrm{nM}$ fluorescein dye and is amenable to multiplexing.

For applications that necessitate enrichment of a droplet subpopulation, the largest bottleneck of current microfluidic droplet systems is the active sorting of "winners." Until just recently, the fastest fluorescence-activated droplet sorting (FADS) circuits operated at 
$2-3 \mathrm{kHz},{ }^{15,16}$ though even typical single-nozzle droplet generators $(10-12 \mathrm{kHz})$ thoroughly outstrip analysis throughput. One workaround accessible to many is fluorescence-activated cell sorting (FACS), which can sort particles at rates of 50-70 kHz. However, droplets must undergo an additional bulk emulsification step to produce water-in-oil-in-water (w/o/w) double emulsion droplets, which are necessary for compatibility with FACS. ${ }^{17}$ Now, engineered, two-device microfluidic approaches are replacing bulk double emulsification. One approach involves a coaxial flow-focusing device that centers the droplet stream in the channel, ensuring single-droplet encapsulation. ${ }^{18}$ The resulting double emulsion droplets are fairly polydisperse considering they originate from microfluidic processing (CV $=22 \%$, likely due to dispersed phase wetting the PDMS channel walls) but show good discrimination during sorting at $10 \mathrm{kHz}$. A second approach involved re-emulsification using a hydrophilic device (modified via polyelectrolyte deposition), which produced highly monodisperse double emulsions $(\mathrm{CV}=2.5 \%)$. FACS analysis at $10-15 \mathrm{kHz}^{19}$ provided 100,000-fold enrichment. The microfluidic double emulsions were stable to heating and freezing, and controllably changed size in response to changes in osmotic pressure.

In addition to w/o/w stabilization, there are many other microfluidic strategies for preparing cell-like or bead-like particles that should be equally compatible with FACS. Microfluidic droplet-templated gel-shell beads (GSBs) (Figure 2A) proved to be an alternative to w/o/w double emulsions. ${ }^{20} \mathrm{GSBs}$ are the product of cooling droplets of agarose, alginate polyanion and assay reagent solution. Once cool, treatment of the gelled emulsion with PAH polycation creates a polyanion/polycation complex, forming a thin semipermeable shell that prevents diffusion of species $>2 \mathrm{kDa}$ out of the bead. After sorting GSBs using FACS $(15-20 \mathrm{kHz})$, recovery of GSB content was simply a matter of disassembling the polyelectrolyte shell at elevated $\mathrm{pH}$.

Compared to single emulsion generation, the re-emulsification step to produce double emulsion droplets typically occurs with a lower throughput, which can take upwards of an hour even for modest libraries. Directly processing the droplets circumvents the complexities of w/o/w sample preparation. An elegant microfluidic circuit that sorts droplets at rates up to $30 \mathrm{kHz}$, exceeding the sorting rates of double emulsions using FACS, replaced the wall between the two collection channels with a gapped divider (Figure 2B) to enable higher flow rates without droplet breakup. ${ }^{21}$ A mock screen with high- and low-fluorescence droplet populations exhibited low false positive and false negative rates $(<1 \%)$. The speed of the PMTs and data acquisition hardware is the limiting factor for throughput.

\section{CONSIDERATIONS FOR DROPLET-BASED ASSAYS}

\section{Molecular retention}

Though droplets serve as ultra-miniaturized reaction vessels, microplate wells they are not. The rigid, plastic microplate grid ensures that each microwell reaction remains discrete and self-contained throughout the screen. Sample adsorption and luminescence detection mode notwithstanding, the well walls are not a consideration. Conversely, the chemical and physical properties of the continuous and dispersed phases ultimately dictate the boundary integrity of droplets. Droplet-scale assay development therefore necessarily entails an examination of assay compatibility with emulsification reagents. 
In order for droplets to serve as effective vessels, they must retain all reaction components starting materials and products - for the duration of the reaction. Most assays use fluorophore probes as their readout, but this can be problematic since hydrophobic molecules partition out of droplets into the continuous phase ("leaking"). ${ }^{22}$ Fluorophore exchange not only reduces assay sensitivity but also increases the false positive rate as probe transfers from hit droplets to negative droplets. A predictive model of enzymatic assay performance considered parameters such as incubation time, droplet size, enzyme catalytic efficiency, and the permeability of a "leaky" probe molecule (here, a fluorescent product) across the droplet interface. ${ }^{23}$ The model predicts that the signal-to-noise ratio generally increases, peaks, and then decays as probe diffuses from the droplet while the reaction consumes substrate. Even without knowledge of the exchange mechanism, this model can help identify reaction conditions of maximal sensitivity, especially with regards to optimal incubation time prior to detection.

Structure-optimized fluorogenic detection reagents exhibit maximum sensitivity and selectivity balanced with minimized disruption of activity in the process they detect. Since droplet exchange has never been a consideration in the design of most commercially available probes, adapting them to droplet-scale reactions usually involves a comprehensive evaluation of probe and product partitioning into the continuous phase. For instance, a fluorogenic probe of MMP-2 activity is the peptide $\mathrm{H}_{2} \mathrm{~N}-\mathrm{RA}$-DapQ-LGLP-FAM (AnaSpec, Hayward, CA). MMP-2-catalyzed cleavage of the L-G amide bond liberates the fluorescein reporter (FAM) from the fluorescence quencher $(\mathbf{Q})$ under slightly alkaline conditions. Importantly, FAM remains tethered to a set of small, nonpolar residues $\left(\mathrm{H}_{2} \mathrm{~N}\right.$-GLP-FAM) that would facilitate partitioning into a nonpolar continuous phase and exchanging into nearby droplets. A more droplet-compatible MMP-2 probe would swap the positions of FAM and $\mathbf{Q}$, such that proteolytic cleavage leaves the fluorophore tethered to the ionized arginine and terminal residues after cleavage.

If commercial probes are not suitable for use in droplets due to unfavorable partitioning, several straightforward modifications now address the issue. Based on previous work, ${ }^{24}$ sulfation of coumarin provides essentially $\mathrm{pH}$-independent negative charge to the reporter dye, confining it in droplets up to $24 \mathrm{~h}$ with no observed exchange. ${ }^{25}$ Further glycosylation of the sulfo-coumarin reporter afforded fluorogenic glycosidase probes. Oligonucleotides served a similar role when attached to a fluorogenic phosphotriesterase probe, ensuring its retention. ${ }^{20,26}$ This modification only reduces enzymatic activity $\sim 2$-fold, providing an elegant and extremely general approach as oligonucleotides are commercially available with a wide variety of chemical handles for functionalization using mild chemistry and predictable chromatographic preparation.

There are also simple, non-synthetic avenues to deter probe or analyte exchange, such as modification of the aqueous phase. For instance, bovine serum albumen (BSA) is an aqueous phase additive that is well known to increase droplet stability and inhibit exchange of coumarin and fluorescein derivatives with mineral oil. ${ }^{22,27}$ Similarly, sucrose and dextran mitigate exchange of resorufin with mineral oil. ${ }^{28}$ These inert additives are a simple and cost-effective method to preserve droplet readout. The $\mathrm{pH}$ of the aqueous phase can also affect retention. Modification of an HIV-1 protease assay buffer $\mathrm{pH}$ from the kit-provided 
system (sodium acetate buffer, $\mathrm{pH}$ 4.7) to a more alkaline system (MES buffer, $\mathrm{pH}$ 6.5) readily ionized the positive control inhibitor, pepstatin A, preventing partitioning into the continuous phase. ${ }^{29}$

Several physicochemical parameters influence the retention of fluorophores inside droplets. The most important criterion seems to be the partitioning coefficient, $\log \mathrm{D}$. Highly hydrophilic dyes $(\log \mathrm{D}<-7)$ are retained regardless of buffer $\mathrm{pH}$, surfactant identity or concentration (Figure 3). ${ }^{30}$ Slightly hydrophobic proteins retain better when labeled with highly hydrophilic dyes. Less hydrophilic dyes retain by optimizing other parameters. For example, lower concentrations of surfactant increase retention, but may lead to droplet instability. This finding supports a mechanism for droplet exchange that relies on inverse micelle formation as increasing surfactant concentration begins to exceed critical micelle concentrations. ${ }^{22}$ Alternatively, Pickering emulsions that employ partially fluorinated silica nanoparticles (NPs) can stabilize droplets instead of the common PFPE-PEG block copolymer surfactants. ${ }^{31}$ Silica NPs $(1.5 \% \mathrm{w} / \mathrm{w}$ dispersed in the oil phase) stabilized droplets and prevented exchange of the hydrophobic fluorophore resorufin where a polymer surfactant $(2 \% \mathrm{w} / \mathrm{w})$ was unable to do so.

\section{Cell-based assays}

Assay miniaturization in droplets affords single-cell analysis over large populations, which is crucial when preserving cellular heterogeneity leads to discoveries that bulk measurements miss. Protein evolution exemplifies such experiments, wherein each cell harbors one variant of a mutant gene library. The wide availability of tools for genetically manipulating yeast and bacteria make these systems the most common hosts for such experiments. Cell encapsulation also enables detection and analysis of specific genomic, transcriptomic, proteomic and metabolomic states. However, cells are acutely sensitive to their environment, and thus assessment of continuous phase oil/surfactant toxicity and gas permeability is usually necessary. The closed droplet system does not readily allow for replenishment of cell media or removal of secreted waste and as such, diminished long-term cell viability may preclude some applications. Culture of single yeast and bacteria cells in picoliter droplets suspended in fluorinated oil/surfactant systems over the course of 4-5 days is possible, ${ }^{32,33}$ with encapsulated E. coli cell cultures demonstrating $~ 80 \%$ viability in droplets after 5 days. ${ }^{34}$

Liquid culture of single yeast and bacteria in droplets is straightforward, but mammalian cells must usually adhere to a solid substrate for culture. In addition to their ability to prevent small molecule leakage, the layers of adsorbed silica NPs that define Pickering emulsions can also serve as rigid supports for adherent cell culture. ${ }^{35}$ Fibroblast and cancer cell culture on nanoparticle-stabilized interfaces are viable up to 3 days, exhibiting similar morphologies to cells grown on polystyrene substrates. Similarly, encapsulating cancer cells inside a thin layer of alginate prior to calcium-induced gelation yields multicellular spheroids in high throughput $(\sim 1 \mathrm{kHz}) .{ }^{36}$ As the cells become confluent, their morphology differs significantly from free spheroids due to the confinement pressure as cells push against the alginate shell (Figure 4); encapsulated cells pack more closely and only the outermost cells proliferate. Confinement alters the phenotypic state of peripheral cells, 
imbuing them with "invasive" qualities since they remain elongated and hypermotile even after dissolution of the alginate shell. Thus, multicellular spheroids could be part of cellbased assays of tumor growth inhibition.

Gel matrices are also common encapsulation agents for mammalian cell culture. Cells growing in a 3D environment better mimic conditions in vivo and exhibit different morphologies than cells grown in a 2D monolayer. ${ }^{37}$ These hydrogel environments are typically created using UV-mediated free radical reactions, which can be cytotoxic. Recent droplet-templated PEG/hPG hydrogel sphere preparations involved more biocompatible thiol-ene click reactions. ${ }^{38}$ Using high loading densities, encapsulated lymphoblast and fibroblast viabilities surpass $75 \%$. Thiol-ene click chemistry also finds use in the fabrication of droplet-templated hyaluronic acid/PEG/fibrinogen hydrogel beads laden with human mesenchymal stem cells, ${ }^{39}$ which possess short-term viability of $\sim 70 \%$ and cultures persist up to 4 weeks. Gelled matrices like these are highly permeable to small molecules, and may need polyelectrolyte shells ${ }^{20}$ to maintain readout for screening.

Droplet compartmentalization is also useful for preserving the link between the cell and its environment. This link is critical in assays of secreted (or displayed) enzymes and metabolites, and even cell lysates, extending the reach of assay development to cytosolic proteins with cell-impermeable probes or probe products. ${ }^{40}$ Cell lysis is also necessary for identification of cells or cell states through digital PCR analysis or next-generation DNA sequencing (NGS). Commercial surfactant mixtures usually require extra scrutiny, though, since the surfactants that disrupt cell membranes can influence droplet stability, and proteinase $\mathrm{K}$ or pepsin digestion (common lysis protocol components) may produce indiscriminate enzyme or peptide FRET probe hydrolysis. Several successful examples of cell lysis include bacterial/yeast cell lysis ${ }^{13,19,20,40-42}$ and mammalian cell lysis. ${ }^{43-48}$

\section{Oil/surfactant compatibility}

Ideally, the continuous phase is a completely inert medium that defines the droplet and transports it through the microfluidic circuit. However, the choice of both oil and surfactant stabilizer can significantly affect assay performance. Surfactant choice impacts molecular retention ${ }^{30,31}$ and oil toxicity and gas permeability influence cell viability. The continuous phase should also impart thermostability if downstream emulsion processing involves PCR. Continuous phase biocompatibility is another important consideration. For instance, the efficiency of cell-free protein expression in droplets is highly variable depending on the continuous phase. ${ }^{26}$ Presumably, interfacial protein adsorption and denaturation is partially responsible for this effect, and therefore, influences all droplet-based enzymatic assays. BSA and other additives can ameliorate protein adsorption. Incorporating PEG into the dispersed phase of Pickering emulsions inhibits protein absorption to the silica NPs and facilitates an enzymatic assay that is not possible in its absence. ${ }^{31}$

Fluorinated oils are among the most popular continuous phases in droplet microfluidics. The PFPE-PEG di- and tri-block copolymer surfactants most commonly used to stabilize droplets are expensive and difficult to synthesize, and as such, alternative biocompatible fluorosurfactants are a welcome addition to the droplet microfluidics toolbox. An easily synthesized nonionic PFPE-Tris surfactant $(2 \% \mathrm{w} / \mathrm{w})$ stabilizes droplets well enough to 
undergo w/o/w double emulsification using two different devices. ${ }^{49}$ Furthermore, the PFPETris surfactant is compatible with both enzymatic assays and cell culture.

Another simple and economical route to droplet stabilization relies on electrostatic interactions between surface-active additives. Jeffamine and other positively-charged diamine additives in the aqueous phase interact with the carboxylic acid of the perfluorinated polyether Krytox at the interface, imparting both stability and biocompatibility to the droplets (Figure 5). ${ }^{50}$ Emulsions of aqueous-phase Jeffamine $(0.75 \%)$ and oil-phase Krytox (1.8\%) are thermostable, withstanding 40 rounds of PCR amplification. In addition to PCR, FRET-based protein assays and DNA amplification via recombinase polymerase amplification are also compatible with this "dynamic" surfactant.

\section{Sample processing and the experimental workflow}

The key challenge of droplet-based screening is library distribution. In other words, how does one deliver one copy (or ideally, many copies) of a library member to a droplet? And, how does one execute this maneuver with throughput to match droplet generation and/or sorting rates? Nucleic acid libraries can be stochastically diluted such that one copy is encapsulated and then amplified or translated in situ. This distribution philosophy also holds true for individual cells, and is useful for detecting and classifying cell subpopulations based on "omic" parameters. In addition to being efficient protein expression systems, cells are convenient vehicles for library distribution and find extensive use in microfluidic directed evolution. Using a vehicle (e.g., cell, bead) addresses the issue of delivering multiple copies of a single library member into a single droplet. Cells are effective carriers of certain molecular classes (DNA, RNA, proteins), but feature heterogeneous expression profiles and are tedious to culture. Droplet-templated DNA-functionalized hydrogel particles circumvent the difficulties of cell culture. ${ }^{51}$ Encapsulating these particles in cell-free expression reagent facilitates the translation of protein gene products inside the hydrogel, followed by diffusion throughout the droplet.

Unlike biomolecular libraries, distribution of synthetic chemical libraries into droplets for functional screening represents a unique and largely unmet challenge. In HTS facilities, screening concentrations of 1-10 $\mu \mathrm{M}$ are common, and the result of transferring aliquots from concentrated stock microplates to assay microplates using automated pin tool arrays. Currently, adapting compound libraries for microfluidic processing involves "sipping" droplets from each well into a tube, which preserves compound identity via spatial encoding. ${ }^{52,53}$ Sipping systems rely on the microplate paradigm, which caps library size at $\sim 10^{6}$ members and requires an additional layer of engineered robotic automation to control the sipping process. Even if this is an acceptable strategy for modest libraries, existing compound library stocks are kept in DMSO and need to be reformatted (Figure 6) for use with droplet microfluidics since only small amounts of organic solvent are tolerable. Alternatively, using a capped cartridge "suspension hopper" introduces one-bead-onecompound (OBOC) combinatorial library beads into a circuit for encapsulation into droplets. ${ }^{29}$ The polyvalent synthesis resin particles inherently deliver multiple library member copies to a single picoliter-scale droplet, an event that the hopper can reproduce over 200,000 bead distributions. Once encapsulated, photolytic cleavage of compound from 
the bead surface provides sufficiently high concentrations (> $30 \mu \mathrm{M})$ for screening in a UV dose-dependent fashion.

Some cell-based assays require certain distribution parameters, such as investigating the interactions between two or more cell types. Microfluidic sorting can now enrich droplets co-encapsulating single cells from two or more populations. ${ }^{54}$ Two populations of Her 2 cells were differentially stained, mixed at equal density, and stochastically distributed into droplets for sorting at a constricted junction. Droplets containing a single cell of each type prior to and after sorting were $2.2 \%$ and $76.7 \%$ of the population, respectively. Broadening the parameters to include more than one cell of each type results in enrichment from $3.5 \%$ to 97.6\%. Cell clumping and droplet instability, which skew the Poisson distribution, are the limiting factors for enrichment.

Collection and reinjection of droplets into devices that act as stand-alone modules for discontinuous assay workflow operations is commonplace. The inherent stability of perfluorous emulsions facilitates this modular approach to process integration, which can interface diverse operations: addition, dilution, enrichment and removal of droplet content, for instance, using separate picoinjection, paired droplet-coalescence and droplet-splitting circuits, or combinations thereof (Figure 7). The flexibility of current microfluidic "hardware" components has recently enabled the development of increasingly complex assays. Indeed, experiments featuring three- and four-device workflows can decouple the effects of one operation on a subsequent downstream operation, more precisely control assay measurement, and incorporate operations that would otherwise be impossible to implement on-chip. ${ }^{33,34,48,55,56}$ Moreover, droplet collection for batch off-chip incubation improves the throughput of the screening workflow; incubation times can be modulated freely for large droplet populations without the design and fabrication constraints imposed by fullyintegrated circuit architectures, where all droplet operations occur within the same circuit.

\section{THE CURRENT SCOPE OF DROPLET-BASED SCREENING}

\section{Assays}

Perhaps the most prevalent assays performed in droplets today interrogate enzymatic activity using dual-labeled FRET probes for fluorescence detection. Such probes can, in theory, transduce the activity of any enzyme that catalyzes bond formation or breakage, including transferase, ligase, hydrolase and lyase activity. Barring molecular retention considerations, their practical implementation is straightforward, as in the case of fluorogenic peptide probes for protease detection or TaqMan PCR probes for DNA detection.

Should probe synthesis prove nontrivial, enzymatic cascade assays facilitate detection of enzymes whose functions cannot currently be monitored directly. Moving signal transduction downstream of enzyme function also enables the use of native substrates, ensuring proper activity of enriched mutant populations in directed evolution screens. An enzymatic cascade assay that links a user-defined oxidase with horseradish peroxidase (HRP) can measure the consumption or production of metabolites by a single cell. ${ }^{32}$ As the metabolite of interest is oxidized, $\mathrm{H}_{2} \mathrm{O}_{2}$ is generated and subsequently reacted with Amplex Red to produce fluorescent resorufin. Similarly, detection of ethanol-producing bacteria with 
a cascade assay is possible by linking alcohol oxidase (AOx) activity to HRP activity via $\mathrm{H}_{2} \mathrm{O}_{2}$ production and concomitant reporting through the Amplex Red/resorufin system above. ${ }^{33}$ Another cascade assay detects cellulase activity in single encapsulated yeast cells (Figure 8 ) on the substrate carboxymethyl cellulose (CMC) by linking it to hexose oxidase (HOx). ${ }^{57}$ As cellulase hydrolyzes $\mathrm{CMC}$, HOx catalyzes the oxidation of product monosaccharides and generates $\mathrm{H}_{2} \mathrm{O}_{2}$, which ultimately results in conversion of quenched aminophenyl fluorescein into fluorescein via a second peroxidase.

Similar in concept, activity-fed translation (AFT) assays link activity of the target enzyme to translation of a separate fluorescent reporter. ${ }^{58}$ For example, phenylacylated amino acid hydrolysis transduces penicillin acylase (PAC) activity by producing amino acids for an amino acid-deficient expression reaction mixture. Amino acid production initiates translation of a fluorescent reporter protein (GFP). By including the PAC gene in the reaction with a small amount of the deficient amino acid, the assay proceeds in an autocatalytic loop, increasing its sensitivity. The assay can even be coupled to ddPCR amplification of the PAC and GFP genes to increase sensitivity.

Enzymatic catalysis is a convenient and robust paradigm to amplify the response from binding events, especially when in conjunction with antibody binding to signal the presence of a particular analyte (i.e. ELISA). Since ELISA requires multiple washing steps, beads displaying capture antibodies first isolate the antigen and enzyme-linked secondary antibody prior to compartmentalization. If [antigen] is always lower than [bead] and much lower than the droplet population, only one enzyme will ever be present inside a droplet. This beadbased ELISA method was performed in femtoliter droplets to detect single molecules of prostate specific antigen (PSA), a biomarker for prostate cancer. ${ }^{2}$ Conjugation of the secondary antibody to $\beta$-galactosidase produced a detectable fluorescent readout within 10 min, with detection of $46 \mathrm{fM}$ [PSA], 100-fold lower than standard ELISAs.

Exploiting catalysis to observe macromolecular binding also creates a general strategy for protein detection that relies on the use of a dual-functional probe. ${ }^{59}$ When the protein target is absent, an inhibitor moiety on the probe prevents enzymatic turnover of a fluorogenic substrate. Alternately, when the probe binds to the protein target, steric effects disrupt enzyme inhibition, catalyzing formation of fluorescent product. Unlike enzyme-catalyzed signal amplification strategies that use antibodies, this methodology does not require any washing steps. The approach has selectively detected 4 proteins (avidin, MGMT, SNAP-tag, and lactoferrin) using dual functional probes with a sulfonamide group that prevents turnover of fluorescein diacetate by human carbonic anhydrase II.

Dual-labeled probes are typically synthesized via rational design, which requires detailed knowledge of the target. However, it is also possible to develop probes for unknown or uncharacterized pathogenic targets using selection, such as chimeric DNAzyme fluorogenic sensors of unique bacterial pathogens. ${ }^{60}$ When a particular identifying molecule binds the sensor, it assumes a conformation that specifically cleaves one phosphodiester bond, separating quencher from fluorophore. These probes have detected pathogenic bacteria in unprocessed blood samples, facilitating rapid diagnostic analysis. ${ }^{13}$ 
Beyond enzymatic activity, protein-protein interactions account for many phenotype changes. Binding tends to occur at large, shallow topologies that are commonly labeled "undruggable." Nevertheless, fluorescence polarization measurements of protein-protein binding constants in picoliter droplets ${ }^{61}$ open interesting possibilities for the discovery of lead compounds that disrupt these interactions. The methodology employs a two-channel laser-induced fluorescence (LIF) system that irradiates droplets with linearly polarized light and measures the degree of fluorescence depolarization.

Most droplet assays feature probes that are homogeneously distributed throughout the assay volume, though to meet this condition, cell-based assays may require lysis, secretion, or membrane permeability of probe products created in cellulo. Despite this, standard live/dead cell assays using propidium iodide and 6-carboxyfluorescein diacetate generate sufficient signal in droplets for the detection of single bacteria passing through a channel constriction. ${ }^{34}$ Even without the aforementioned dispersion measures, detection of encapsulated fluorescent cells under high-throughput flow conditions is possible.

\section{Applications}

Directed evolution is undoubtedly the most mature mode of droplet-based discovery. The mutant library, either in cells or as single gene copies, is distributed into droplets, expressed, and assayed for a particular phenotype. "Winner" droplets are sequestered, and the emulsion is broken to recover the genotype for subsequent rounds of mutagenesis or characterization. Three rounds of compartmentalized screening starting from a library of $8 \times 10^{5}$ promiscuous arylsulfatases (PAS) $)^{40}$ yielded a pool of $\sim 100$ variants exhibiting improved activity. The top $10 \%$ of cloned and sequenced mutants contained a 6 -fold improved variant. Droplettemplated GSBs were critical in the evolution of phophotriesterase (PTE) activity, an enzyme that neutralizes pesticides and nerve gas agents. ${ }^{20}$ One round of FACS produced a PTE variant with $\sim 8$-fold improved catalytic efficiency. A four-device microfluidic platform has been used to improve the catalysis of the X-motif ribozyme against a trans substrate. ${ }^{56}$ Droplets in the top $1 \%$ were enriched after nine rounds of selection, where library mutagenesis was performed initially and after rounds 2,4 and 6 . Two different 5-error mutants were isolated that increased turnover $\sim 28$-fold by conferring reduced product inhibition.

A library of $10^{5}$ yeast that underwent UV-mediated whole-genome mutation were encapsulated and screened for a-amylase activity against a starch substrate. ${ }^{62}$ The top $0.72 \%$ of fluorescent droplets possessed cells with $63 \%$ higher amylase production and $35 \%$ higher yield than the non-sorted fraction. Analysis of 60 sorted yeast variants revealed a strain with $>2$-fold amylase production and a higher growth rate in culture than the parental strain. UVinduced genome-wide mutation has also been combined with whole-genome sequencing to identify and map proteins that facilitate secretion of amylase. ${ }^{63}$ Two rounds of mutagenesis and screening isolated six clones suitable for whole-genome sequencing. The best among these had a 6-fold improvement in amylase secretion over the parental strain. A total of 330 point mutations ( 248 in ORFs) that alter 146 different proteins were identified. Classification of the affected genes pointed to, among other things, alteration of cell secretory pathways. Follow-up experiments using gene knockouts confirmed their involvement in enhanced 
amylase secretion. Perhaps most importantly, the mutated genes identified through sequencing are novel candidates for further protein engineering efforts.

An enzymatic cascade assay has been coupled with NGS to enrich and analyze cell libraries for variants that overconsume or overproduce metabolites. ${ }^{32}$ The microfluidic platform could discriminate xylose consumption between yeast variants; one particular xylose overconsumer contained three adjacent copies of the xylose isomerase gene $X Y L A$, which converts xylose to xylulose.

Similarly, encapsulated glycosidase variants were sorted based on activity and the winning mutant genes were sequenced to reveal residues essential for enzyme function. ${ }^{41}$ Mapping the variability of each amino acid residue between the unsorted library and the mutants enables comparison of mutational tolerance for specific residues across an entire family of related proteins to reveal enzyme phylogeny. A further selection isolated mutants that showed activity after a heat challenge. Comparing the enrichment of residues in the sorted pool to the unsorted pool revealed several point mutations that stabilized the enzyme structure; notably, S325C increased $\mathrm{T}_{50}$ by $5.3{ }^{\circ} \mathrm{C}$. These analyses provide invaluable information for directed evolution efforts and general proteomics.

Droplet microfluidics can also support bioprospecting campaigns that may be precursory to directed evolution efforts. Individual bacteria in a soil sample from a wheat stubble field have been assayed for cellobiohydrolase activity. ${ }^{64}$ Soil bacteria were analyzed either directly (activity-based selection) or after growth on agar (growth-based selection), and the $2 \%$ most fluorescent droplets were sorted for each population. Cellobiohydrolase activity in the activity-based selection population was 17 -fold higher than the growth-based selection population. This difference is indicative of challenges with culturing soil bacteria in the lab and would be undetectable in microplate assays, which require bacterial growth. NGS of sorted bacteria revealed a larger taxonomic diversity in the activity-based selection versus the growth-based selection, and an enrichment of Paenibacillaceae and Bacillaceae in each respective population.

Reverse-transcription PCR (RT-PCR) has emerged as a powerful tool to probe the transcriptome of single cells in droplets. Creating gene expression profiles for a large population of cells can provide powerful insights into cell heterogeneity, response to chemical or pathogenic challenges, regulatory pathways and disease etiology. However, cell lysate strongly inhibits RT-PCR in picoliter droplets. To enable droplet RT-PCR, single-cell lysates were diluted through paired-droplet coalescence, fractionated via passive splitting, and combined with RT-PCR reagents via picoinjection. ${ }^{43}$ The efficacy of this approach was determined by detecting PTPRC transcripts in a mixture of $\sim 50,000$ Raji and PC 3 cells, where only Raji cells contain the PTPRC transcript. The PTPRC detection rates for Raji and PC 3 cells were $88 \%$ and $0.3 \%$ whereas positive-control GAPDH transcript detection rates were $99 \%$ and $88 \%$, respectively. RT-PCR could similarly differentiate droplets containing transcripts of the cancer biomarker vimentin from a mixed population of over 130,000 cancer cells (DU145) and B-lymphocytes. ${ }^{44}$ Sorted droplets underwent genetic sequencing and showed enriched SNPs in $R B 1$ and $C D K N 2 A$, two known tumor suppressor genes in DU145 cells. 
Further research has demonstrated single-droplet barcoding using hydrogel particles that display unique photocleavable ssDNA primers ("inDrop"). ${ }^{45}$ The entire transcriptome of > 10,000 single mouse embryonic stem cells was barcoded during RT-PCR in nanoliter droplets and sequenced with NGS. Statistical analysis (PCA and t-SNE) of the data revealed previously-characterized subpopulations in both the primitive endoblast lineage and epiblast lineage, but also uncharacterized subpopulations, such as one expressing high levels of heatshock proteins and ER components and low levels of pluripotency factors.

The limiting factor of droplet-based RT-PCR is mRNA capture efficiency using poly(dT) primers. "Drop-seq" (Figure 9), a companion technology to inDrop, captures mRNA on a co-encapsulated bead displaying primers with a unique cell barcode, or STAMPs (single-cell transcriptomes attached to microparticles). ${ }^{46}$ RT-PCR is performed in batch after the emulsion has been broken and the beads collected, improving capture efficiency to $\sim 13 \%$, compared to $\sim 7 \%$ for inDrop. Drop-seq was used to analyze $\sim 45,000$ mouse retinal cells; PCA and t-SNE analyses divided the expression profiles into 39 distinct populations. Amacrine types were distinguished based on six known markers, but other genes with the potential to distinguish between 21 different amacrine subpopulations with similar gene expression were also identified.

mRNA capture on beads has also facilitated analysis of VH-VL antibody pairings for $>10^{6}$ B cells. ${ }^{47}$ After mRNA capture, the emulsion was broken, the beads were pooled and reemulsified to perform overlap-extension RT-PCR, which links the VH and VL gene products together. These linked gene products were sequenced to investigate the frequency of "public pairings" (pairings found in separate individuals), allelic inclusions (a single B cell making two or more antibodies), and to identify broadly neutralizing antibodies in healthy individuals. $>20 \%$ of all heavy chains paired with promiscuous VL junctions. Moreover, the most abundant promiscuous light chains were "public," whereas the most abundant heavy chain sequences were usually specific to an individual. VL allelic inclusion was found in $0.4 \%$ of VH-VL clusters.

Similar to direct gene expression profiling, mapping chromatin in single cells can inform on the regulatory networks that control expression. Nucleosomes derived from thousands of mouse embryonic stem (ES) cells have been genetically-barcoded in microfluidic droplets and then subjected to ChIP-seq (chromatin immunoprecipitation followed by sequencing) to discover epigenetic substructures within a cell population. ${ }^{65}$ Both ES and embryonic fibroblast (MEF) nucleosomes were immunoprecipitated with anti-H3K4Me2, selecting for a lysine dimethylation that signals promoter and enhancer binding. Clustering of the aggregated read profiles showed a tight MEF distribution whereas ES cells were comprised of three loose subpopulations that track with the enhancement of known pluripotency factors, revealing a gradient of lineage priming.

Genomic analysis enables rapid identification of cell markers for diagnostic purposes. For instance, digital PCR was used to identify the 7 most common $K R A S$ oncogene mutants and a single $B R A F$ mutant using circulating tumor DNA (ctDNA) in blood plasma as a minimally-invasive cancer diagnostic. ${ }^{66}$ Fifty patient samples were analyzed in multiplex assays with different concentrations of TaqMan probe to detect each mutation. When 
compared directly with tumor biopsies, $92 \%$ of samples returned the correct genotype. The multiplexed $K R A S$ assay false positive rate was $6 \%$.

Similarly, droplet PCR has been used to identify mutations in SETBP1 in mononuclear blood cells from patients with juvenile myelomonocytic leukemia, where SETBP1 mutations putatively lead to poor prognosis. ${ }^{67}$ Using FAM- and HEX-labeled TaqMan probes to identify mutants and wild-type $S E T B P 1$, respectively, droplets were sorted and the amplified DNA was sequenced. Samples from $>70$ patients collected over time showed that SETBP1 mutations were present in $35 \%$ of patients at diagnosis and occupied a much larger allelic fraction at relapse. 5-year event-free survival for these patients was $18 \pm 9 \%$ compared to 51 $\pm 8 \%$ for patients without $S E T B P 1$ mutations.

Droplet compartmentalization can also overcome amplification bias when sequencing a single cell genome. Emulsion multiple display amplification (eMDA) was performed by lysing a single cell and amplifying the gDNA fragments at a concentration of $\sim 1$ per droplet. ${ }^{68}$ gDNA fragment sequestration flattens amplification bias since each fragment is roughly amplified to the same level once the PCR reagents are exhausted. After NGS, eMDA was compared to bulk genome sequencing and other single-cell methods. eMDA resulted in $72.3 \%$ genome coverage, higher than the other single-cell methodologies at the same sequencing depth.

Segregation within a miniaturized environment affords detailed parallel analysis of the single-cell secretome. The cytochrome profiles of single Jurkat T cells encapsulated in droplet-templated agarose gel beads have been detected upon stimulation. ${ }^{69}$ Cells and beads displaying antibodies for IL-2, TNF- $\alpha$ and IFN- $\gamma$ were coencapsulated and incubated for up to 2 days. Upon gelation, the agarose beads were stained with fluorescent reporter antibodies for each of the cytokines and sorted using flow cytometry. From a pool of $\sim 8,000$ individual cells, FACS analysis revealed 8 different subpopulations based on the combination of cytokines secreted, with $\sim 57 \%$ of cells secreting all three. The subpopulations were further probed based on the amount of cytokine secreted by a given cell, for instance, finding that the $10 \%$ highest IL-2 secreting-cells also secrete higher amounts of the other two cytokines.

The effect of secreted factors on cell phenotype in a local environment can also be probed in droplets. Jarosz et al. discovered that some bacteria produce a diffusible factor that induces the $\left[G A R^{+}\right]$prion in yeast. ${ }^{70}$ The $\left[G A R^{+}\right]$prion is responsible for glucose repression and enables yeast to grow using a diverse array of carbon sources. Yeast displaying the [GAR$\left.{ }^{+}\right]$ phenotype produce less alcohol, which is beneficial for the bacteria, while $\left[G A R^{+}\right]$yeast have a competitive advantage when multiple carbon sources are present. [gar $\left.{ }^{-}\right]$cells grown in selective media arrested their growth within the first generation, but when yeast cells were co-encapsulated with an inducing bacterial strain, 12-h incubations produced yeast cells with the $\left[G A R^{+}\right]$phenotype. Furthermore, $80 \%$ of the yeast population was $\left[G A R^{+}\right]$after $48 \mathrm{~h}$, which represents a 80,000-fold increase over the spontaneous prion-switching rate.

The power of droplet microfluidic platforms as diagnostic tools for human disease also extends to pathogen detection. Measuring infectivity of a virus to a particular cell type has been accomplished by co-encapsulating murine norovirus particles with murine macrophage 
RAW cells, incubating droplets for a full viral replication cycle, and performing RT-PCR amplification of viral DNA with TaqMan probes. ${ }^{48}$ This methodology correlates well with standard plaque assays, but on a much accelerated time frame (hours vs. weeks).

Quantitation of miRNA in plasma samples revealed elevated levels of a miRNA in the blood of patients with colorectal cancer. The workflow included encapsulating plasma samples in droplets and performing EXPAR isothermal amplification of miRNA with probes to quantitate the Let-7a miRNA. ${ }^{14}$ miRNAs were detected with a sensitivity of 50 copies $/ \mathrm{mL}$ plasma, whereas RT-qPCR needed $\sim 1000$ copies $/ \mathrm{mL}$, making their system $\sim 20$-fold more sensitive than the "gold standard" assay. Elevated levels of Let-7a were found in the plasma samples of patients with colorectal cancer compared to healthy patients, which correlated nicely with RT-qPCR analysis.

\section{THE BACK-END OF DISCOVERY: WHO'S WHO \& WHAT'S WHAT}

\section{Enzyme kinetics}

After screening generates a pool of variants with desirable properties, the next step in many applications is characterization of the subpopulation performance or composition. Directed evolution screens, for instance, produce a number of variants with new or enhanced function. Likewise, compound library screens may produce a number of inhibitor leads against the target of choice. Subsequent kinetic characterization and secondary assays occur in microplates, but the large reaction volume squanders precious reagent. Furthermore, reagent addition to wells is rarely simultaneous and several minutes may pass before the first measurement, a large problem for reactions with fast kinetics. Miniaturized fluid manipulation, however, provides exquisite control over reagent addition and reaction timecourse, delivering platforms for the precise measurement of formal enzymological rate constants.

A two-device microfluidic platform measured enzyme inhibition kinetics by generating sets of fluorescently-encoded picoliter droplets with varying [inhibitor] and constant [enzyme]. ${ }^{71}$ These droplets were mixed together, different [fluorogenic substrate] were added via picoinjection, and reaction progress was observed over time at 6 different measurement points in an incubation channel. Droplet [inhibitor] was barcoded by adding fluorescein to a stream of enzyme and inhibitor prior to combination with a second enzyme stream. Relative flow rates for each input were modulated to produce droplets with different [inhibitor], which is determined by the fluorescein intensity readout. Similarly, different inhibitors can each be encoded with unique barcoding dyes.

Using endpoint analysis in droplets to acquire transient data can require hundreds to thousands of droplet measurements to accrue high-confidence data. Other recent microfluidic strategies eschew endpoint detection by interrogating a set of single-droplet reactions over a period of time. A more elegant approach uses two inversely oscillating flow programs to produce fluorescently-encoded [substrate] gradients and a third inlet to provide constant [enzyme] immediately prior to droplet generation, producing $>400$ distinct picoliter-scale droplets across the range of [substrate]. ${ }^{72}$ Reaction progress in individual droplets is monitored in a serpentine channel based on [barcoding dye]. Stroboscopic 
illumination yields wide-field fluorescence images of the droplet train, enabling extraction of the enzyme kinetic parameters.

Reaction process monitoring is also possible using larger droplets. Automated production of nanoliter droplets from open-bottom tubes immersed in oil produced a set of 24 spatiallyencoded reactions for interrogation in tubing over a programmed time-course as the droplet train moves back and forth through the detection region. ${ }^{73}$ Paired enzyme and substrate droplets for all reaction sets are merged simultaneously in the tubing and reaction progress monitored at multiple time points. Droplet train production from microwells was also possible by positioning a piece of tubing inside a pipette tip filled with oil, submerging the tip into the well, and using negative pressure to pull aqueous segments in oil into the tubing. ${ }^{74}$ Sampling nanoliter droplets while continuously introducing a known [substrate] into a well consisting of known [enzyme] produces variable concentration gradient profiles over more than 100 droplets. The droplet train is scanned back and forth through the detection region to make enzyme kinetic measurements. Similar to standard microplate experiments, however, the reaction proceeds between production of the first and last droplets.

\section{Separation techniques}

Integration of separation technologies and droplet-scale sample manipulation is quite challenging, but raises some intriguing possibilities addressing the problem of single-droplet identification and analysis. Mass spectrometry (MS) is a particularly tantalizing detection strategy for screening because it enables the use of native substrates, ideal for evolving enzymes with proper selectivity and obtaining accurate enzyme kinetics measurements. Online electrospray ionization (ESI-MS) analysis of droplets containing assay reagent and compound sourced from "reformatted" microplate wells served as a droplet-scale protease inhibitor screening platform. ${ }^{53}$ Hits from the assay were compounds that exhibited low relative abundance of a non-fluorogenic peptide cleavage product ion relative to an isotopically-labeled internal standard. Improvements in detection sensitivity feature prominently in a recent method that affords detection of femtomole quantities of protein in surfactant-stabilized picoliter-scale droplets with ESI directly from the microchip into the mass spectrometer source. ${ }^{75}$ Fluorinated oils and surfactants feature significantly reduced background ionization in positive ion mode.

ESI is most commonly used to interface microfluidic samples with MS, but limits droplet composition to volatile buffer systems that enhance aerosol desolvation. An alternative ionization method, electrostatic-spray ionization (ESTASI), to a microfluidic nanoliter droplet flow occurs through a channel featuring a "spyhole" that is open to atmosphere. ${ }^{76}$ An electrode beneath the device generates high-voltage wave pulses that electrostatically spray the droplet through the spyhole and into the mass spectrometer while the oil phase flows to waste. Unlike ESI, this technique successfully samples droplets comprised of basic solutions and even pure water. Fluorinated oils either produced inconsistent signal or masked it completely, which prompted the use of 1,2-dichloroethane as the continuous phase.

The two major limitations of MS droplet analysis are (1) the scan rate of the instrument can only accept droplet throughput of $<5 \mathrm{~Hz}$, and (2) the destructive nature of detection, which 
demands a priori knowledge of droplet content, presumably through spatial or isotopic encoding. These constraints conspire to cap library size at $\sim 10^{5}$ members. That doesn't mean, however, that MS is unsuitable for discovery efforts. Instead, it can prove most beneficial directly interrogating a smaller library derived from the hit space of a primary screen. Indeed, MS detection successfully identified 24 cathepsin B inhibitor leads from a library of 1,280 FDA-approved compounds, including 11 structural motifs not previously associated with cathepsin inhibition. ${ }^{53}$

Historically, capillary electrophoresis (CE) has outclassed MS quantitative accuracy. Two recent reports each describe microfluidic CE circuits for separating and quantitating the contents of microfluidic droplets. The most notable design aspect from one was the use of a hydrophobic and oleophilic foam pad that passively absorbs oil phase, transitioning samples from segmented flow in tubing to a capillary zone electrophoresis or capillary gel electrophoresis separation channel. ${ }^{77}$ However, injection of entire picoliter or nanoliter droplets as plugs results in sample overloading and poorly resolved separations. Sampling droplets into a glass capillary tube within a hydrophobic PDMS T-junction avoids this issue by using the natural difference in surface chemistry to separate the oil and aqueous phases. ${ }^{52}$ The collection capillary acts as the sample reservoir on a standard 4-arm glass CE device, which effectively decouples droplet sampling from injection and affords better separation performance. This droplet CE library screening approach surveyed 140 test compounds for protein kinase A inhibition. Similarities in application and apparatus design invite comparison with the MS-based system to evaluate their merits for library screening. It is apparent that MS has obviated droplet CE as an assay detection tool as it is more robust (CE is prone to channel surface passivation, which is deleterious to separation performance and reproducibility), more easily interfaced with droplet microfluidics, and higher throughput. Furthermore, miniaturization has enabled the use of isotopically-labeled internal standards in droplet MS, improving analyte quantitation and leaving instrumentation cost as CE's major advantage over MS.

\section{WHAT'S NEXT? FUTURE CHALLENGES}

Larger, more diverse chemical and biological libraries greatly increase the odds of discovering new or improved functional molecules. Directed evolution is a prime example application that involves surveying millions of variants and compartmentalization plays the key role of associating genetic information and chemical function in these experiments. Encapsulation of DNA, RNA, display-type, or even cellular libraries in water-in-oil emulsion droplets ${ }^{78}$ critically enables discovery of functions beyond binding, such as catalysis and inhibition. Although droplet generation throughput was at one point limiting, microfluidic droplet-based evolution experiments are becoming increasingly common owing to the advances this review has covered.

A major reason for the success of directed evolution experiments in droplets is the ease of library generation and distribution. This same reason partly explains the huge discrepancy in size of biological library ( $>10^{5}$ members) and chemical library $\left(\sim 10^{3}\right)$ screening experiments to date. Academic researchers particularly have access to very few large, platebased libraries from which to sip, prompting exploration of new library synthesis, delivery 
and distribution strategies. One example of such a scalable methodology for distributing > $10^{5}$ chemical library members could entail the use of synthesis beads, wherein single droplets house single beads, ${ }^{29}$ and libraries are the products of split-and-pool combinatorial synthesis.

Another critical obstacle that likely contributes to the dearth of compound screening-based experiments in droplets is the lack of suitable droplet-scale library indexing (i.e., a strategy for identifying library members after screening). Optical encoding has been the most common droplet indexing strategy. ${ }^{79}$ However, the spectral resolution of fluorescent dyes as well as the sensitivity and dynamic range of the decoding optics limit the number of possible barcodes $\ll<10^{5}$. A magnetic nanoparticle encoding strategy coupled to optical encoding increased coding capacity 10 -fold, ${ }^{80}$ suggesting that multiplexing numerous orthogonal coding systems is a viable option moving forward. Likewise, a route to DNA-encoded combinatorial solid-phase libraries ${ }^{81}$ is compatible with bead screening in droplets (Figure 10). ${ }^{29}$ The information density of polynucleotides can yield encoding languages with the capacity to index $>10^{7}$ library members. Indeed, numerous single-cell assays have already implemented DNA barcodes to associate diverse mRNA strands and nucleosome fragments to their original cell. ${ }^{45,46,65}$ As the cost and read length of NGS continue to improve, DNA barcodes are likely to become the front-runner encoding technology in droplet microfluidics.

Despite recent advances, droplet sorting throughput remains a bottleneck for most screening platforms. Separating "winners" from "losers" by selection is always the optimal choice because throughput does not scale with library size. Very few selection strategies for microfluidic-droplet systems exist, but this does not necessarily mean that we are resigned to sort droplets. Innovative assay development could enable a variety of selection paradigms, revolutionizing droplet-based discovery platforms. Continued assay development will expand the utility of droplet-based screening. Phenotypic screening and high-content screening are particularly powerful modes of discovery in microplates that deserve the attention of droplet technology developers.

\section{CONCLUSIONS}

The micrometer plate's tyrant reign over high-throughput experimentation, ranging from public big data science in the Human Genome Project and Molecular Libraries Initiative to industrial drug discovery, is coming to an end. Over the past 5 years, microfluidic droplet technology has made significant advances in the areas of continuous phase chemistry, application development, and microfluidic component engineering and integration. The resulting circuits and instruments seem destined for one purpose: searching ever-expanding haystacks for sharper and shinier needles. Within libraries of cells, compounds, and genes lie super-producers, next-generation enzyme inhibitors, and highly efficient catalysts. The voyage of their discovery begins with forming a single droplet and ends with identifying its contents, a story that is likely to play out manifold in the coming years.

\section{ACKNOWLEDGMENT}

A NIH Director's New Innovator Award to B.M.P. (OD008535) and a DARPA Fold F(x) initiative grant (N66001-14-2-4057) supported this work. 


\section{Biographies}

Alexander K. Price received his Ph.D. in Analytical Chemistry from Kansas State University. Currently, he is a postdoctoral fellow in the Chemistry Department at The Scripps Research Institute (TSRI) in Jupiter, FL. He is interested in small molecule discovery in droplets.

Brian M. Paegel received his Ph.D. in Physical Chemistry from UC Berkeley and completed postdoctoral studies as an NIH NRSA and Pathway to Independence fellow at The Scripps Research Institute (TSRI) in La Jolla, CA. His laboratory operates on the Jupiter, FL campus of TSRI where he is currently an associate professor in the Chemistry Department. He is interested in the rational construction of cell-like vessels, reaction confinement and compartmentalization, and high-throughput experimentation.

\section{REFERENCES}

(1). Chiu DT, Lorenz RM, Jeffries GDM. Anal. Chem. 2009; 81:5111-5118. [PubMed: 19507850]

(2). Shim J-U, Ranasinghe RT, Smith CA, Ibrahim SM, Hollfelder F, Huck WTS, Klenerman D, Abell C. ACS Nano. 2013; 7:5955-5964. [PubMed: 23805985]

(3). Li Z, Leshansky AM, Pismen LM, Tabeling P. Lab Chip. 2015; 15:1023-1031. [PubMed: 25490544]

(4). Leman M, Abouakil F, Griffiths AD, Tabeling P. Lab Chip. 2015; 15:753-765. [PubMed: 25428861]

(5). Abate AR, Weitz DA. Lab Chip. 2011; 11:1911-1915. [PubMed: 21505660]

(6). Paegel BM, Joyce GF. Chem. Biol. 2010; 17:717-724. [PubMed: 20659684]

(7). Zeng Y, Novak R, Shuga J, Smith MT, Mathies RA. Anal. Chem. 2010; 82:3183-3190. [PubMed: 20192178]

(8). Lim J, Caen O, Vrignon J, Konrad M, Taly V, Baret J-C. Biomicrofluidics. 2015; 9:034101034112. [PubMed: 26015838]

(9). Jeong H-H, Yelleswarapu VR, Yadavali S, Issadore D, Lee D. Lab Chip. 2015 Advance Article, DOI:10.1039/C5LC01025J.

(10). Thorsen T, Roberts RW, Arnold FH, Quake SR. Phys. Rev. Lett. 2001; 86:4163-4166. [PubMed: 11328121]

(11). Lim J, Gruner P, Konrad M, Baret J-C. Lab Chip. 2013; 13:1472-1475. [PubMed: 23455606]

(12). Kim M, Pan M, Gai Y, Pang S, Han C, Yang C, Tang SKY. Lab Chip. 2015; 15:1417-1423. [PubMed: 25588522]

(13). Kang D-K, Ali MM, Zhang K, Huang SS, Peterson E, Digman MA, Gratton E, Zhao W. Nat. Commun. 2014; 5:5427. [PubMed: 25391809]

(14). Zhang K, Kang D-K, Ali MM, Liu L, Labanieh L, Lu M, Riazifar H, Nguyen TN, Zell JA, Digman MA, Gratton E, Li J, Zhao W. Lab Chip. 2015; 15:4217-4226. [PubMed: 26387763]

(15). Mazutis L, Gilbert J, Ung WL, Weitz DA, Griffiths AD, Heyman JA. Nat. Protoc. 2013; 8:870891. [PubMed: 23558786]

(16). Schmid L, Weitz DA, Franke T. Lab Chip. 2014; 14:3710-3718. [PubMed: 25031157]

(17). Bernath K, Hai MT, Mastrobattista E, Griffiths AD, Magdassi S, Tawfik DS. Anal. Biochem. 2004; 325:151-157. [PubMed: 14715296]

(18). Lim SW, Abate AR. Lab Chip. 2013; 13:4563-4572. [PubMed: 24146020]

(19). Zinchenko A, Devenish SRA, Kintses B, Colin P-Y, Fischechner M, Hollfelder F. Anal. Chem. 2014; 86:2526-2533. [PubMed: 24517505]

(20). Fischlechner M, Schaerli Y, Mohamed MF, Patil S, Abell C, Hollfelder F. Nat. Chem. 2014; 6:791-796. [PubMed: 25143214] 
(21). Sciambi A, Abate AR. Lab Chip. 2015; 15:47-51. [PubMed: 25352174]

(22). Courtois F, Olguin LF, Whyte G, Theberge AB, Huck WTS, Hollfelder F, Abell C. Anal. Chem. 2009; 81:3008-3016. [PubMed: 19284775]

(23). Chen Y, Gani AW, Tang SKY. Lab Chip. 2012; 12:5093-5103. [PubMed: 23090153]

(24). Woronoff G, El-Harrak A, Mayot E, Schicke O, Miller OJ, Soumillion P, Griffiths AD, Ryckelynck M. Anal. Chem. 2011; 83:2852-2857. [PubMed: 21413778]

(25). Najah M, Mayot E, Mahendra-Wijaya IP, Griffiths AD, Ladame S, Drevelle A. Anal. Chem. 2013; 85:9807-9814. [PubMed: 24079367]

(26). Kaltenbach M, Devenish SRA, Hollfelder F. Lab Chip. 2012; 12:4185-4192. [PubMed: 22885600]

(27). Wu N, Courtois F, Zhu Y, Oakeshott J, Easton C, Abell C. Electrophoresis. 2010; 31:3121-3128. [PubMed: 20803501]

(28). Sandoz PA, Chung AJ, Weaver WM, Di Carlo D. Langmuir. 2014; 30:6637-6643. [PubMed: 24870310]

(29). Price AK, MacConnell AB, Paegel BM. Anal. Chem. 2014; 86:5039-5044. [PubMed: 24761972]

(30). Janiesch J-W, Weiss M, Kannenberg G, Hannabuss J, Surrey T, Platzman I, Spatz JP. Anal. Chem. 2015; 87:2063-2067. [PubMed: 25607822]

(31). Pan M, Lyu F, Tang SKY. Anal. Chem. 2015; 87:7938-7943. [PubMed: 26153615]

(32). Wang BL, Ghaderi A, Zhou H, Agresti J, Weitz DA, Fink GR, Stephanopoulos G. Nat. Biotechnol. 2014; 32:473-480. [PubMed: 24705516]

(33). Abalde-Cela S, Gould A, Liu X, Kazamia E, Smith AG, Abell C. J. R. Soc. Interface. 2015; 12:20150216. [PubMed: 25878135]

(34). Cho S, Kang D-K, Sim S, Geier F, Kim J-Y, Niu X, Edel JB, Chang S-I, Wootton RCR, Elvira KS, deMello AJ. Anal. Chem. 2013; 85:8866-8872. [PubMed: 23937555]

(35). Pan M, Rosenfeld L, Kim M, Xu M, Lin E, Derda R, Tang SKY. ACS Appl. Mater. Interfaces. 2014; 6:21446-21453. [PubMed: 25347285]

(36). Alessandri K, Sarangi BR, Gurchenkov VV, Sinha B, Kießling TR, Fetler L, Rico F, Scheuring S, Lamaze C, Simon A, Geraldo S, Vignjević D, Doméjean H, Rolland L, Funfak A, Bibette J, Bremond N, Nassoy P. Proc. Natl. Acad. Sci. U.S.A. 2013; 110:14843-14848. [PubMed: 23980147]

(37). Paguirigan A, Beebe DJ. Lab Chip. 2006; 6:407-413. [PubMed: 16511624]

(38). Rossow T, Heyman JA, Ehrlicher AJ, Langhoff A, Weitz DA, Haag R, Seiffert S. J. Am. Chem. Soc. 2012; 134:4983-4989. [PubMed: 22356466]

(39). Ma Y, Neubauer MP, Thiele J, Fery A, Huck WTS. Biomater. Sci. 2014; 2:1661-1671.

(40). Kintses B, Hein C, Mohamed MF, Fischlechner M, Courtois F, Leine C, Hollfelder F. Chem. Biol. 2012; 19:1001-1009. [PubMed: 22921067]

(41). Romero PA, Tran TM, Abate AR. Proc. Natl. Acad. Sci. U.S.A. 2015; 112:7159-7164. [PubMed: 26040002]

(42). Lyu F, Xu M, Cheng Y, Xie J, Rao J, Tang SKY. Biomicrofluidics. 2015; 9:044120. [PubMed: 26339319]

(43). Eastburn DJ, Sciambi A, Abate AR. Anal. Chem. 2013; 85:8016-8021. [PubMed: 23885761]

(44). Eastburn DJ, Sciambi A, Abate AR. Nucleic Acids Res. 2014; 42:e128. [PubMed: 25030902]

(45). Klein AM, Mazutis L, Akartuna I, Tallapragada N, Veres A, Li V, Peshkin L, Weitz DA, Kirschner MW. Cell. 2015; 161:1187-1201. [PubMed: 26000487]

(46). Macosko EZ, Basu A, Satija R, Nemesh J, Shekhar K, Goldman M, Tirosh I, Bialas AR, Kamitaki N, Martersteck EM, Trombetta JJ, Weitz DA, Sanes JR, Shalek AK, Regev A, McCarroll SA. Cell. 2015; 161:1202-1214. [PubMed: 26000488]

(47). DeKosky BJ, Kojima T, Rodin A, Charab W, Ippolito GC, Ellington AD, Georgiou G. Nat. Med. 2015; 21:86-91. [PubMed: 25501908]

(48). Tao Y, Rotem A, Zhang H, Chang CB, Basu A, Kolawole AO, Koehler SA, Ren Y, Lin JS, Pipas JM, Feldman AB, Wobus CE, Weitz DA. Lab Chip. 2015; 15:3934-3940. [PubMed: 26304791] 
(49). Chiu Y-L, Chan HF, Phua KKL, Zhang Y, Juul S, Knudsen BR, Ho Y-P, Leong KW. ACS Nano. 2014; 8:3913-3920. [PubMed: 24646088]

(50). DeJournette CJ, Kim J, Medlen H, Li X, Vincent LJ, Easley CJ. Anal. Chem. 2013; 85:1055610564. [PubMed: 24070333]

(51). Thiele J, Ma Y, Foschepoth D, Hansen MMK, Steffen C, Heus HA, Huck WTS. Lab Chip. 2014; 14:2651-2656. [PubMed: 24663810]

(52). Guetschow ED, Steyer DJ, Kennedy RT. Anal. Chem. 2014; 86:10373-10379. [PubMed: 25233947]

(53). Sun S, Kennedy RT. Anal. Chem. 2014; 86:9309-9314. [PubMed: 25137241]

(54). Hu H, Eustace D, Merten CA. Lab Chip. 2015; 15:3989-3993. [PubMed: 26313441]

(55). Beneyton T, Coldren F, Baret J-C, Griffiths AD, Taly V. Analyst. 2014; 139:3314-3323. [PubMed: 24733162]

(56). Ryckelynck M, Baudrey S, Rick C, Marin A, Coldren F, Westhof E, Griffiths AD. RNA. 2015; 21:458-469. [PubMed: 25605963]

(57). Ostafe R, Prodanovic R, Lloyd Ung W, Weitz DA, Fischer R. Biomicrofluidics. 2014; 8:041102. [PubMed: 25379082]

(58). Woronoff G, Ryckelynck M, Wessel J, Schicke O, Griffiths AD, Soumillion P. Chembiochem. 2015; 16:1343-1349. [PubMed: 25914325]

(59). Wang C-W, Yu W-T, Lai H-P, Lee B-Y, Gao R-C, Tan K-T. Anal. Chem. 2015; 87:4231-4236. [PubMed: 25811916]

(60). Ali MM, Aguirre SD, Lazim H, Li Y. Angew. Chem. Int. Ed. 2011; 50:3751-3754.

(61). Choi J-W, Kang D-K, Park H, deMello AJ, Chang S-I. Anal. Chem. 2012; 84:3849-3854. [PubMed: 22455567]

(62). Sjostrom SL, Bai Y, Huang M, Liu Z, Nielsen J, Joensson HN, Svahn HA. Lab Chip. 2014; 14:806-813. [PubMed: 24366236]

(63). Huang M, Bai Y, Sjostrom SL, Hallström BM, Liu Z, Petranovic D, Uhlén M, Joensson HN, Andersson-Svahn H, Nielsen J. Proc. Nat. Acad. Sci. U.S.A. 2015 DOI:10.1073/pnas. 1506460112.

(64). Najah M, Calbrix R, Mahendra-Wijaya IP, Beneyton T, Griffiths AD, Drevelle A. Chem. Biol. 2014; 21:1722-1732. [PubMed: 25525991]

(65). Rotem A, Ram O, Shoresh N, Sperling RA, Goren A, Weitz DA, Bernstein BE. Nat. Biotechnol. 2015 DOI:10.1038/nbt.3383.

(66). Taly V, Pekin D, Benhaim L, Kotsopoulos SK, Le Corre D, Li X, Atochin I, Link DR, Griffiths AD, Pallier K, Blons H, Bouche O, Landi B, Hutchison JB, Laurent-Puig P. Clin. Chem. 2013; 59:1722-1731. [PubMed: 23938455]

(67). Stieglitz E, Troup CB, Gelston LC, Haliburton J, Chow ED, Yu KB, Akutagawa J, Taylor-Weiner AN, Liu YL, Wang Y-D, Beckman K, Emanuel PD, Braun BS, Abate A, Gerbing RB, Alonzo TA, Loh ML. Blood. 2015; 125:516-524. [PubMed: 25395418]

(68). Fu Y, Li C, Lu S, Zhou W, Tang F, Xie XS, Huang Y. Proc. Natl. Acad. Sci. U.S.A. 2015 DOI: 10.1073/pnas.1513988112.

(69). Chokkalingam V, Tel J, Wimmers F, Liu X, Semenov S, Thiele J, Figdor CG, Huck WTS. Lab Chip. 2013; 13:4740-4744. [PubMed: 24185478]

(70). Jarosz DF, Brown JCS, Walker GA, Datta MS, Ung WL, Lancaster AK, Rotem A, Chang A, Newby GA, Weitz DA, Bisson LF, Lindquist S. Cell. 2014; 158:1083-1093. [PubMed: 25171409]

(71). Sjostrom SL, Joensson HN, Svahn HA. Lab Chip. 2013; 13:1754-1761. [PubMed: 23478908]

(72). Hess D, Rane A, deMello AJ, Stavrakis S. Anal. Chem. 2015; 87:4965-4972. [PubMed: 25849725]

(73). Gielen F, Van Vliet L, Koprowski BT, Devenish SRA, Fischlechner M, Edel JB, Niu X, deMello AJ, Hollfelder F. Anal. Chem. 2013; 85:4761-4769. [PubMed: 23614771]

(74). Gielen F, Buryska T, Van Vliet L, Butz M, Damborsky J, Prokop Z, Hollfelder F. Anal. Chem. 2015; 87:624-632. [PubMed: 25496166] 
(75). Smith CA, Li X, Mize TH, Sharpe TD, Graziani EI, Abell C, Huck WTS. Anal. Chem. 2013; 85:3812-3816. [PubMed: 23514243]

(76). Gasilova N, Yu Q, Qiao L, Girault HH. Angew. Chem. Int. Ed. 2014; 53:4408-4412.

(77). Niu X, Pereira F, Edel JB, de Mello AJ. Anal. Chem. 2013; 85:8654-8660. [PubMed: 23957576]

(78). Tawfik DS, Griffiths AD. Nat. Biotechnol. 1998; 16:652-656. [PubMed: 9661199]

(79). Brouzes E, Medkova M, Savenelli N, Marran D, Twardowski M, Hutchison JB, Rothberg JM, Link DR, Perrimon N, Samuels ML. Proc. Natl. Acad. Sci. U.S.A. 2009; 106:14195-14200. [PubMed: 19617544]

(80). Lin G, Makarov D, Medina-Sánchez M, Guix M, Baraban L, Cuniberti G, Schmidt OG. Lab Chip. 2015; 15:216-224. [PubMed: 25353316]

(81). MacConnell AB, McEnaney PJ, Cavett VJ, Paegel BM. ACS Comb. Sci. 2015; 17:518-534. [PubMed: 26290177] 

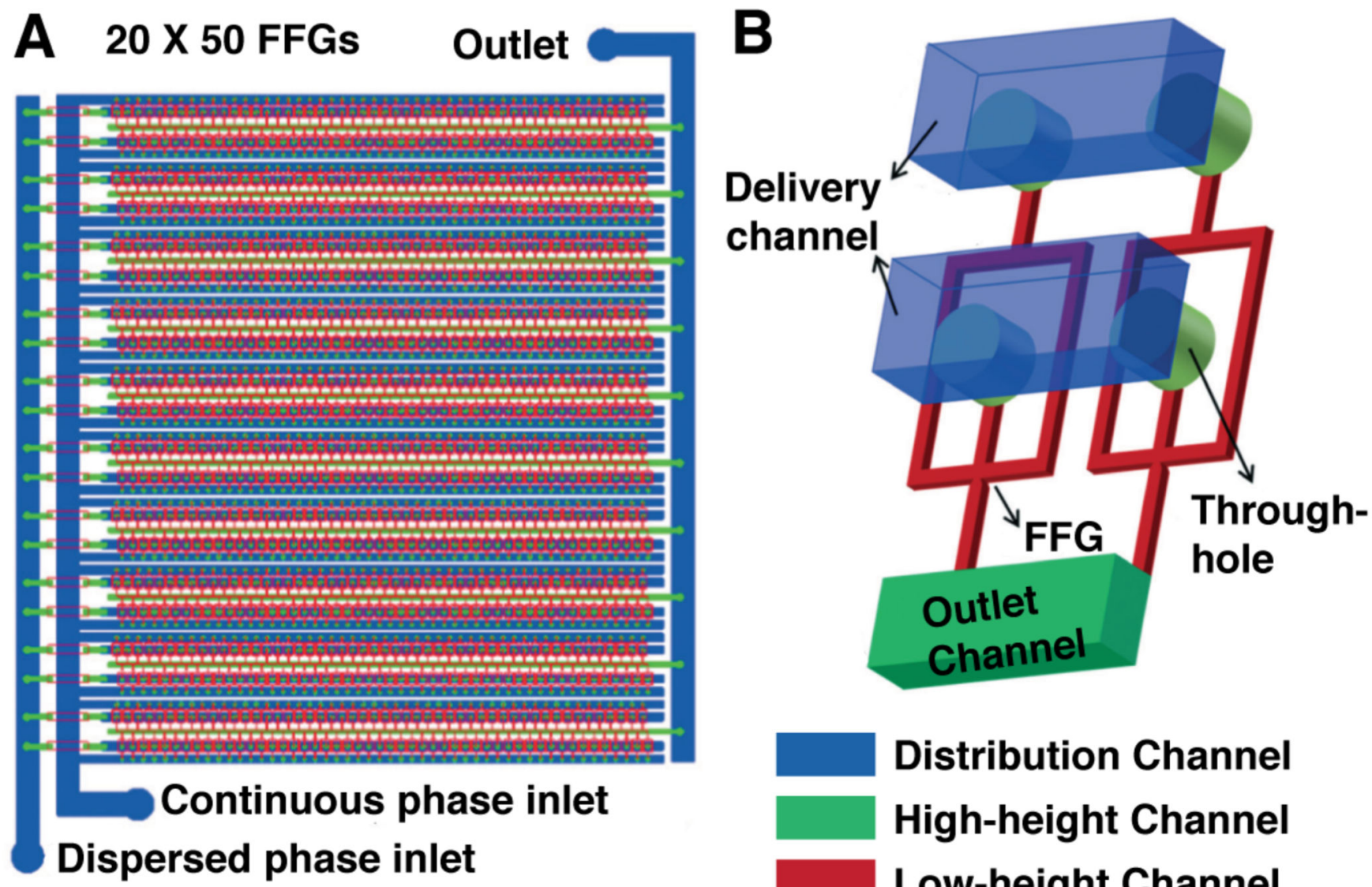

Figure 1.

Ultra-high-throughput droplet generation. (A) The three-dimensional monolithic elastomer device (3D MED) consists of an array of $20 \times 50$ flow-focusing generators (FFGs). (B) Through-hole-containing manifolds enable parallelization of a conventional droplet generation mode for unparalleled scales of production. Adapted from Jeong, H.-H.; Yelleswarapu, V. R.; Yadavali, S.; Issadore, D.; Lee, D. Lab Chip 2015, Advance Article, DOI:10.1039/C5LC01025J (ref 9) with permission of The Royal Society of Chemistry. 


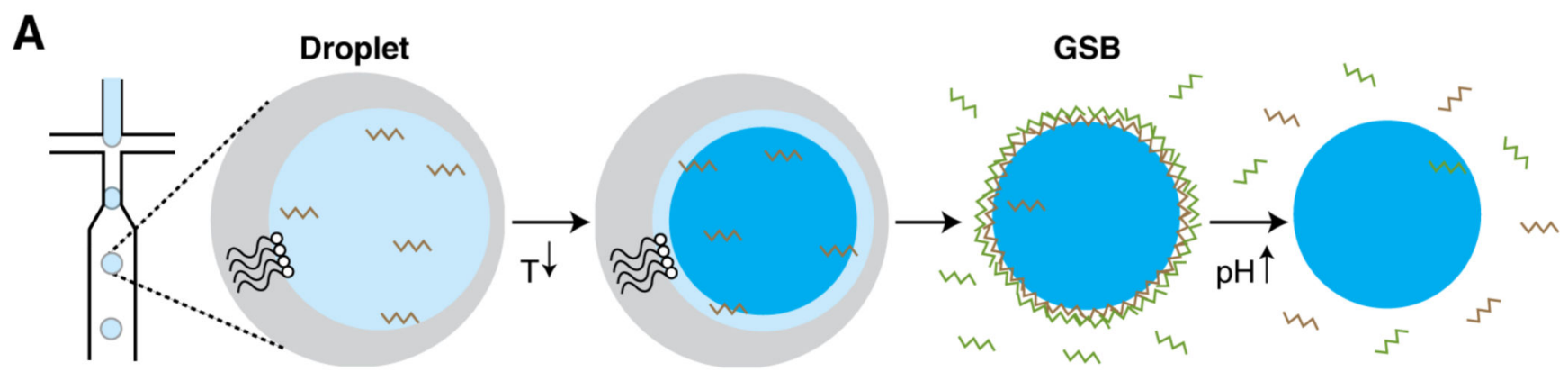

B
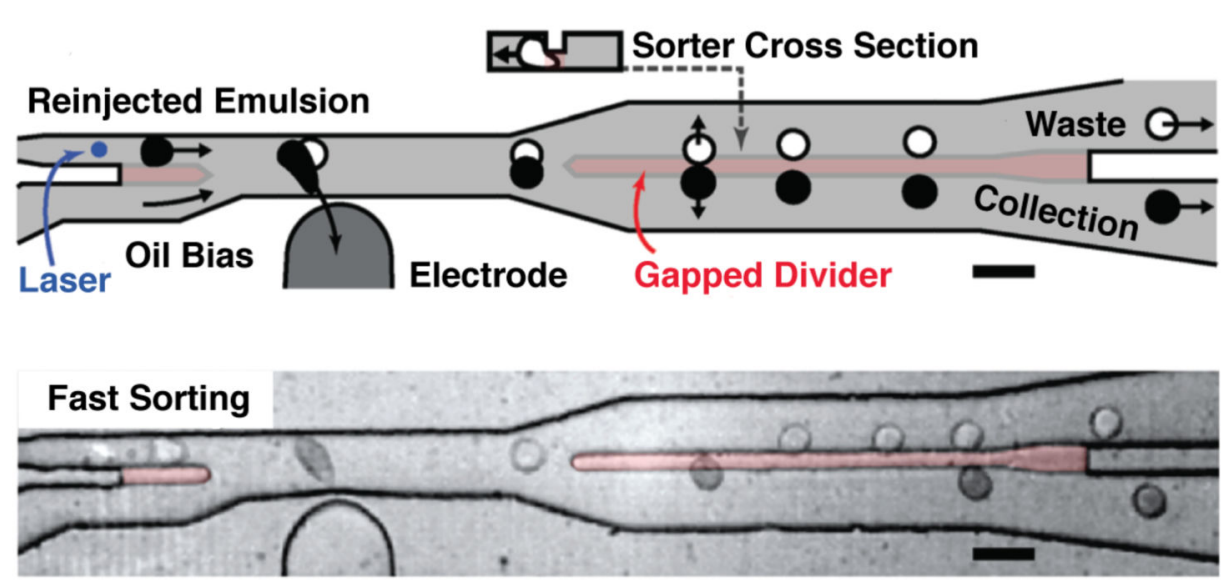

Figure 2.

Enabling technology for sorting. Flow-focusing droplet generation using an agarose/alginate aqueous phase in oil followed by cooling and oil removal generated particles with a thin, semi-porous polyelectrolyte gel. The particles are suitable for conventional FACS-based analysis. The gel-shell beads (GSB) shells could be disassembled at elevated $\mathrm{pH}$ to access contents. Reprinted by permission from Macmillan Publishers Ltd: Nature Chemistry (ref 20), copyright 2014. (B) Ultra-high-throughput sorting at $30 \mathrm{kHz}$ is possible with a redesigned sorting junction. Gapped dividers prevent droplet scission and close positioning of waste and collection streams provide for rapid electrokinetic droplet mobilization after laser-induced fluorescence detection signals a positive event. Scale $=50 \mu \mathrm{m}$ Adapted from Sciambi, A.; Abate, A. R. Lab Chip 2015, 15, 47-51 (ref 21) with permission of The Royal Society of Chemistry. 


\section{Proper surfactant selection}
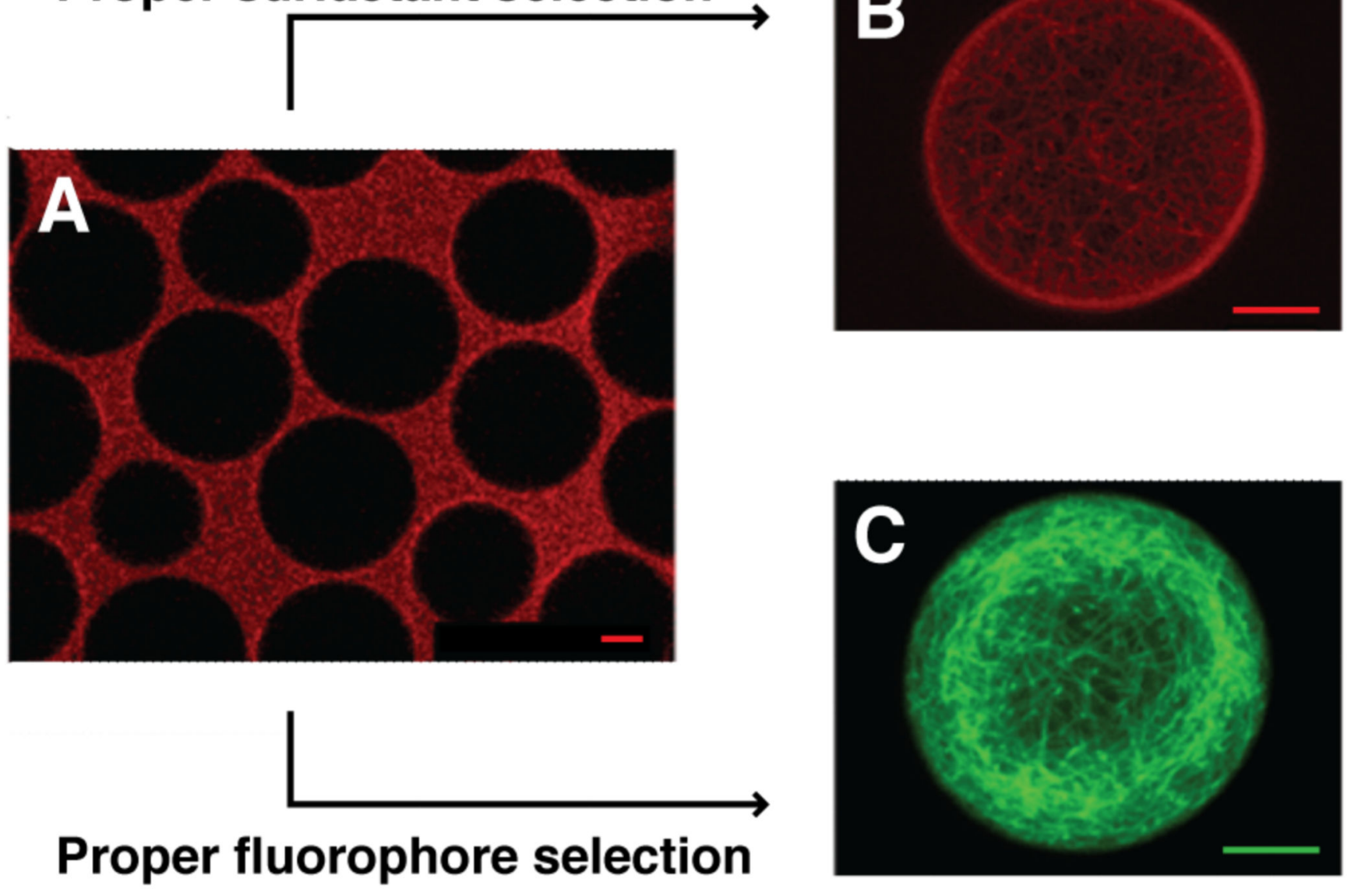

Figure 3.

Retention as a function of dye and surfactant selection. (A) Microtubules stained with ATTO633 immediately partition to the oil phase in triblock co-polymer TRI2500 surfactant. (B) Selection of a higher molecular weight triblock copolymer surfactant TRI7000 properly compartmentalizes the ATTO633-stained protein. (C) Microtubules stained with ATTO488, a more hydrophilic dye, retain properly in TRI2500-stabilized droplets. Scale $=10 \mu \mathrm{m}$ Adapted with permission from Janiesch, J.-W.; Weiss, M.; Kannenberg, G.; Hannabuss, J.; Surrey, T.; Platzman, I.; Spatz, J. P. Anal. Chem. 2015, 87, 2063-2067 (ref 30). Copyright 2015 American Chemical Society. 

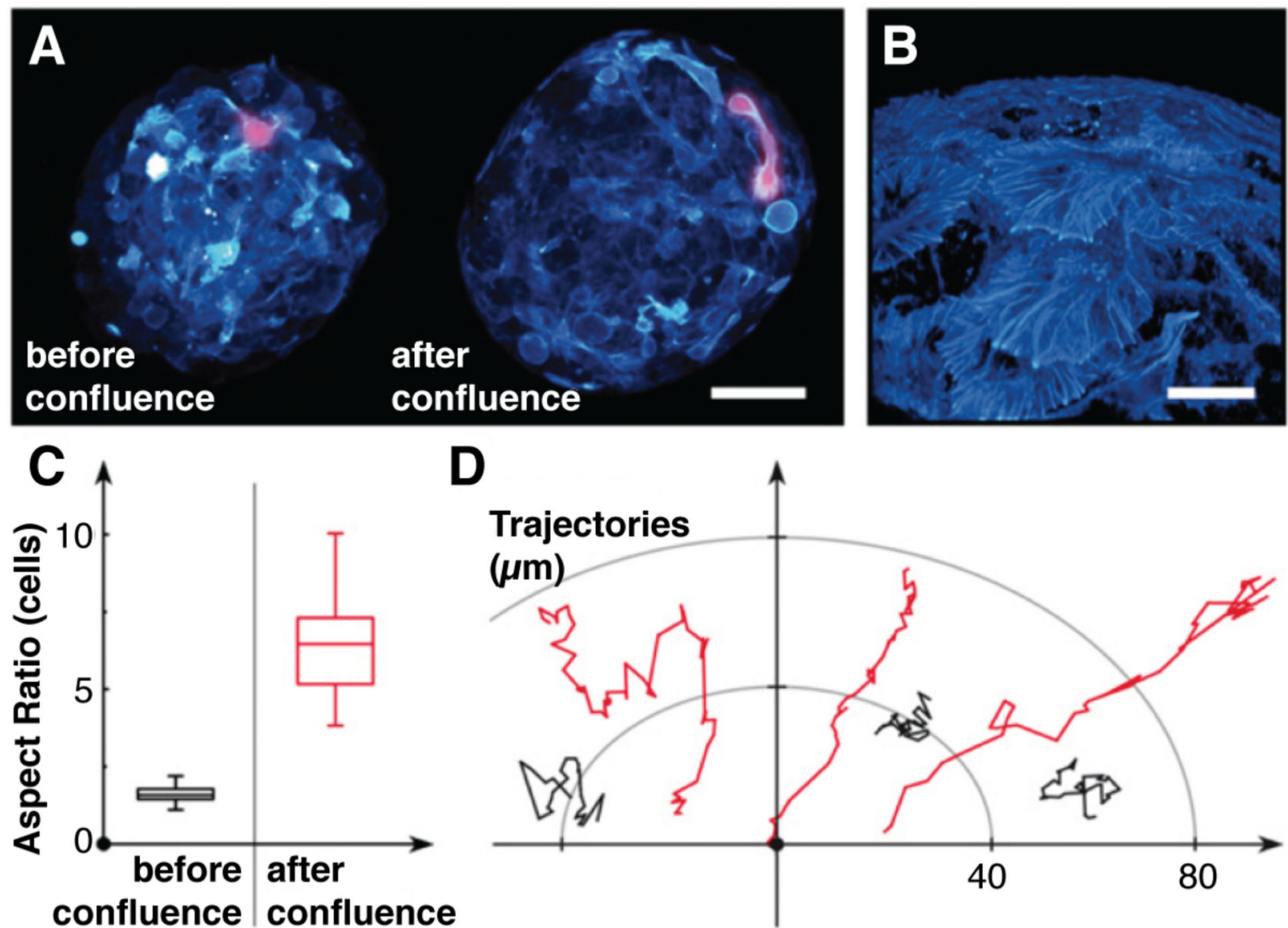

D
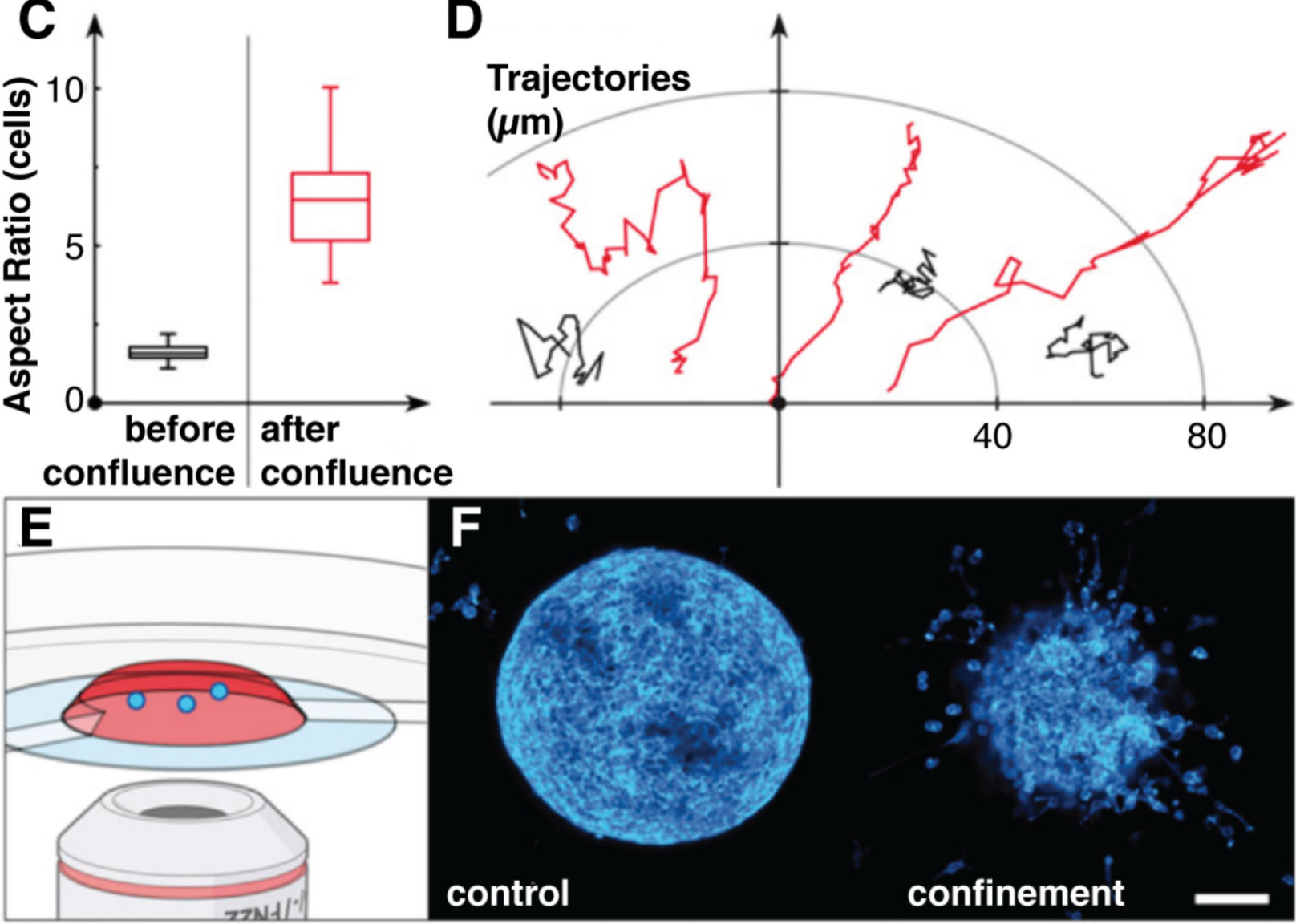

control

confinement

Figure 4.

Confinement and confluence in multicellular spheroid cultures (MCSs). (A) before confluence, cells proliferate in the interior of the gel-shell microcapsule and upon confluence, cover the gel surface with phenotypically different cells, magnified in (B). Quantitation of (C) cell morphology and (D) cell motility before and after confluence reveal the emergence of hypermotile and elongated cells. (E) Confocal fluorescence microscopybased analysis of (F) invasion assays using either spheroids grown freely (control) or confined in gel microcapsules (confinement) support the hypothesis that the confined, 
postconfluent phenotype is different and invasive, readily escaping the collagen matrix where free-range MCSs display benign behavior. Adapted from Alessandri et al. (ref 36) with permission from the National Academy of Sciences. 


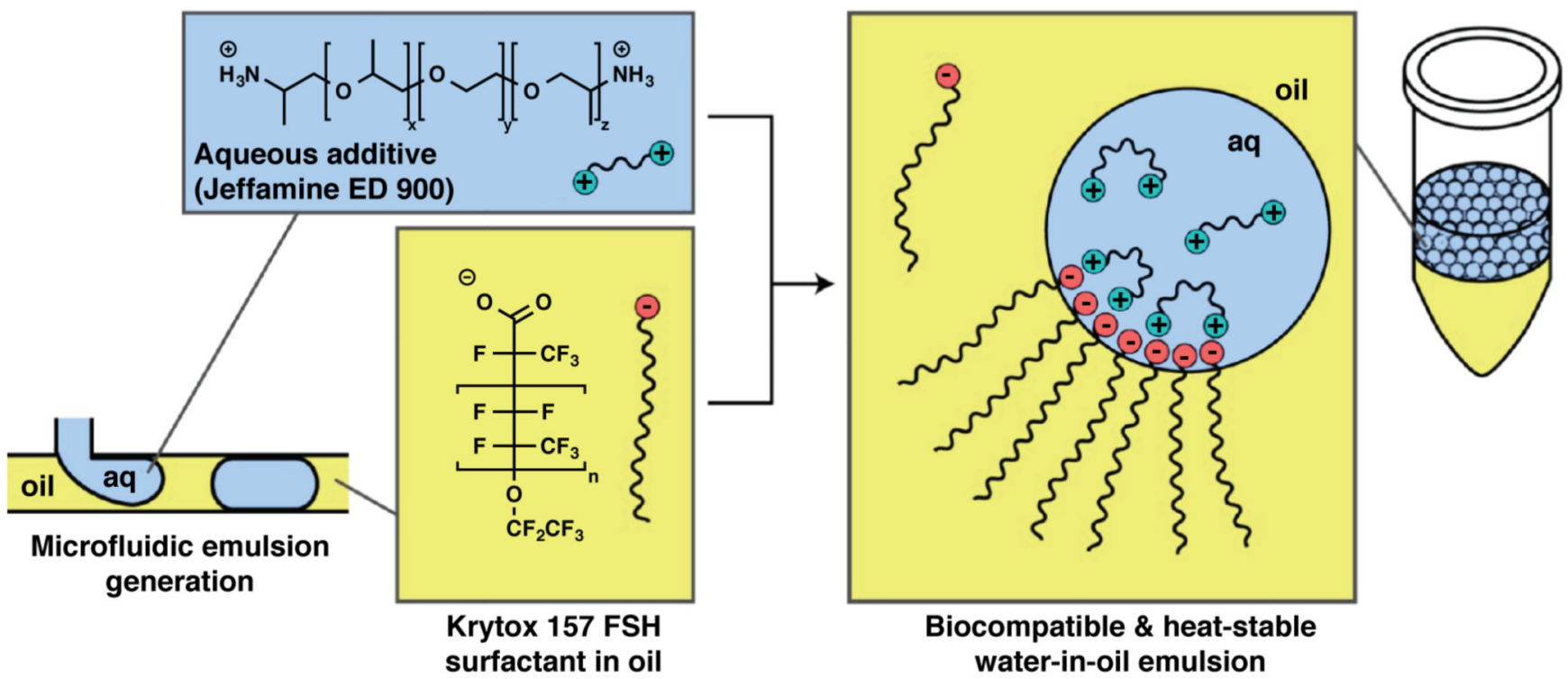

Figure 5.

Aqueous polyetherdiamine Jeffamine associates with the carboxylate headgroups of Krytox157 solubilized in perfluorous oil generating a dynamic surfactant from commercially available starting materials. Microfluidic emulsions are compatible with PCR and protein binding assays. Adapted with permission from DeJournette, C. J.; Kim, J.; Medlen, H.; Li, X.; Vincent, L. J.; Easley, C. J. Anal. Chem. 2013, 85, 10556-10564 (ref 50). Copyright 2013 American Chemical Society. 

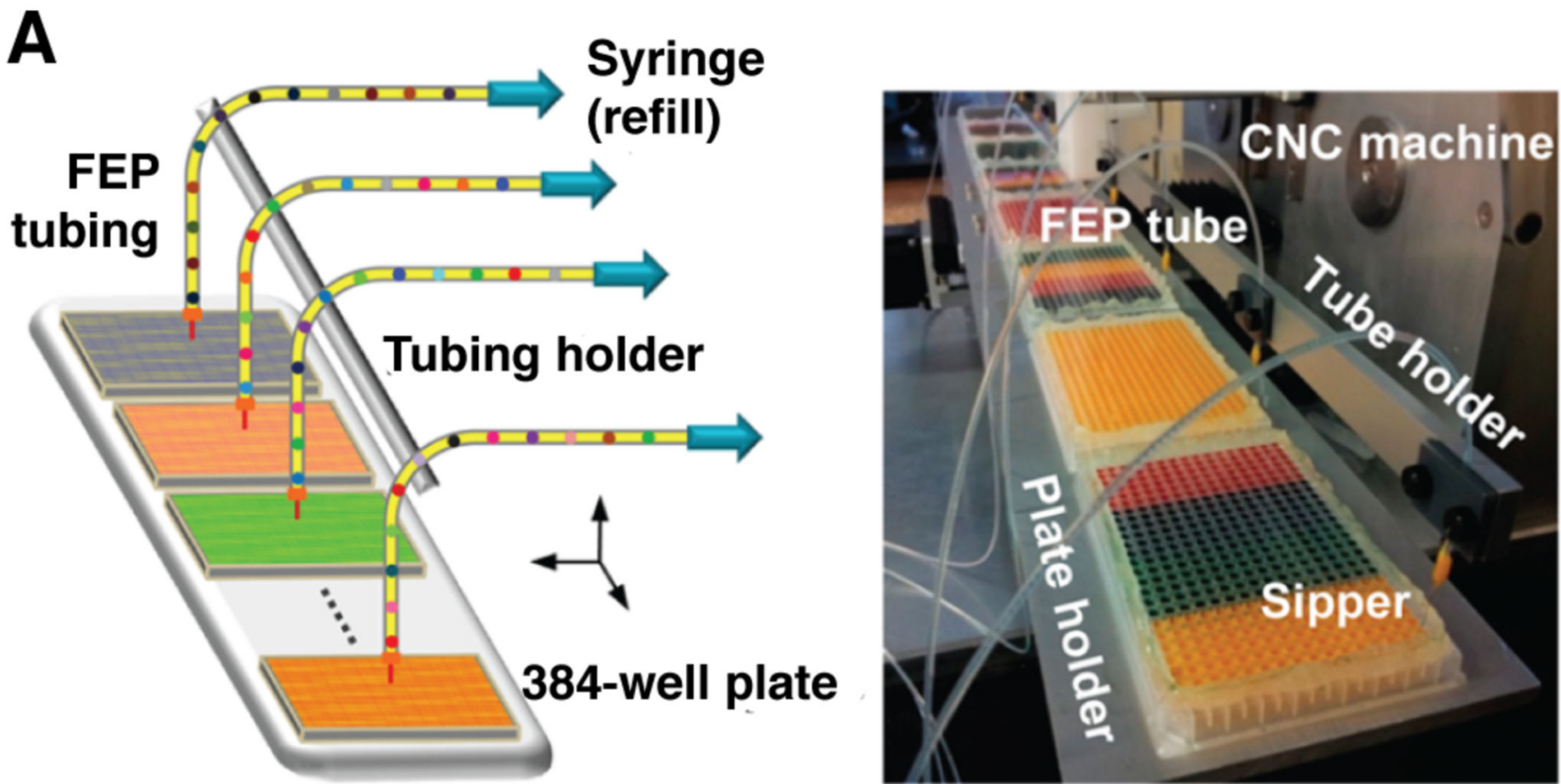

B

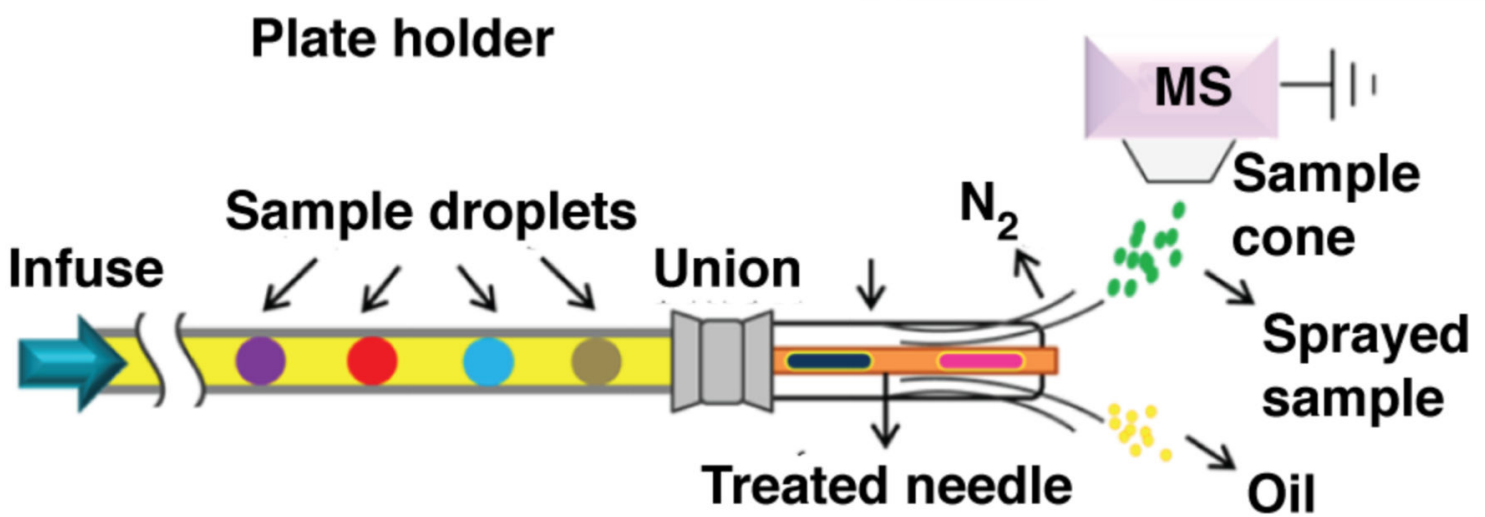

Figure 6.

Compound library sampling and on-line MS analysis in droplets. Microplate reformatting into indexed droplet flows occurs through a high-throughput sipping system that features sample plates submerged below an insulating layer of oil. (B) Sampled compound droplets proceed toward an electrospray ionization MS front end. Adapted with permission from Sun, S.; Kennedy, R. T. Anal. Chem. 2014, 86, 9309-9314 (ref 53). Copyright 2014 American Chemical Society. 


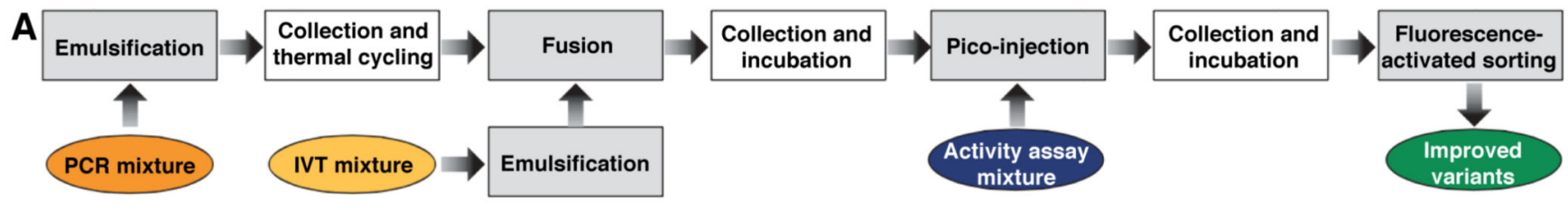

B

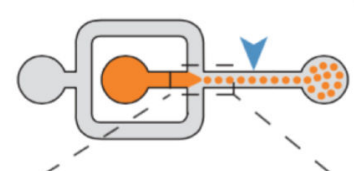

C

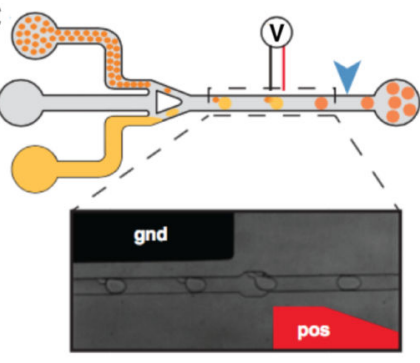

D

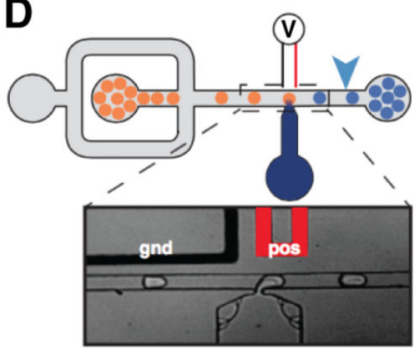

$\mathbf{E}$

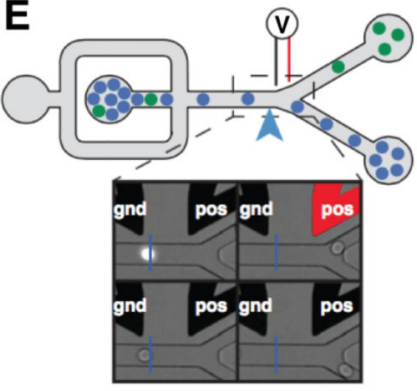

Figure 7.

Modular microfluidic droplet-based discovery workflow. (A) Multiple devices accomplish in serial the workflow tasks, including (B) emulsification, (C) reagent addition via electrocoalescence or (D) pico-injection, and (E) fluorescence-activated sorting. Incubation occurs off-line. Figure adapted from Ryckelynck, M.; Baudrey, S.; Rick, C.; Marin, A.; Coldren, F.; Westhof, E.; Griffiths, A. D. RNA 2015, 21, 458-469 (ref 56) under a Creative Commons License. 


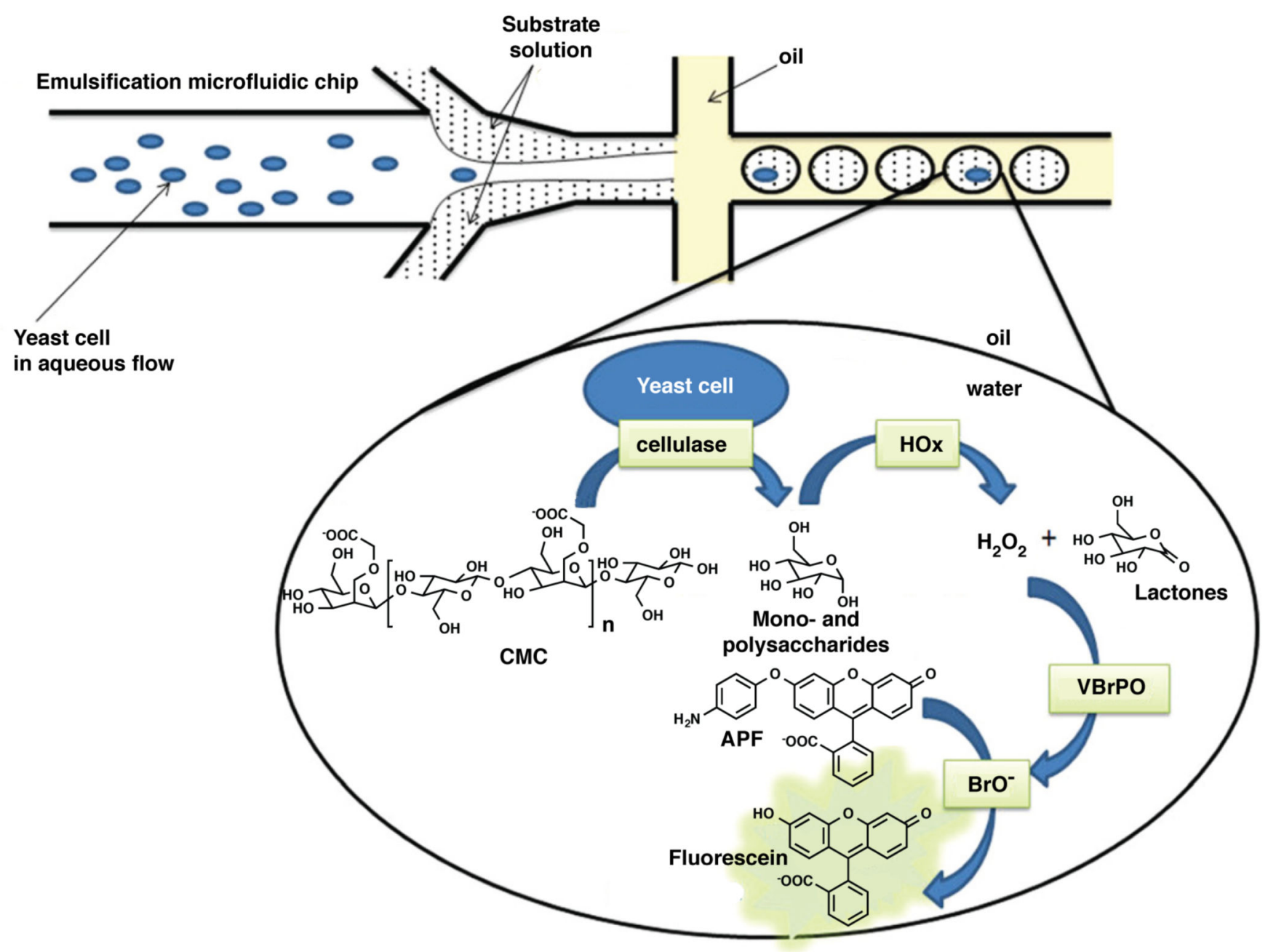

Figure 8.

Compartmentalized cellulase screening platform. Yeast cells expressing the Cel5a cellulase gene secrete the enzyme product into a fluorogenic activity assay reagent.

Carboxymethylcellulase (CMC) digestion yields smaller sugar products, such as glucose, which can participate in a redox cascade through hexose oxidase (HOx) and a vanadium bromoperoxidase (VBrPO), yielding conversion of quenched aminophenyl fluorescein substrate into fluorescent product. Adapted with permission from Ostafe, R.; Prodanovic, R.; Lloyd Ung, W.; Weitz, D. A.; Fischer, R. Biomicrofluidics 2014, 8, 041102 (ref 57). Copyright 2014, AIP Publishing LLC. 
A

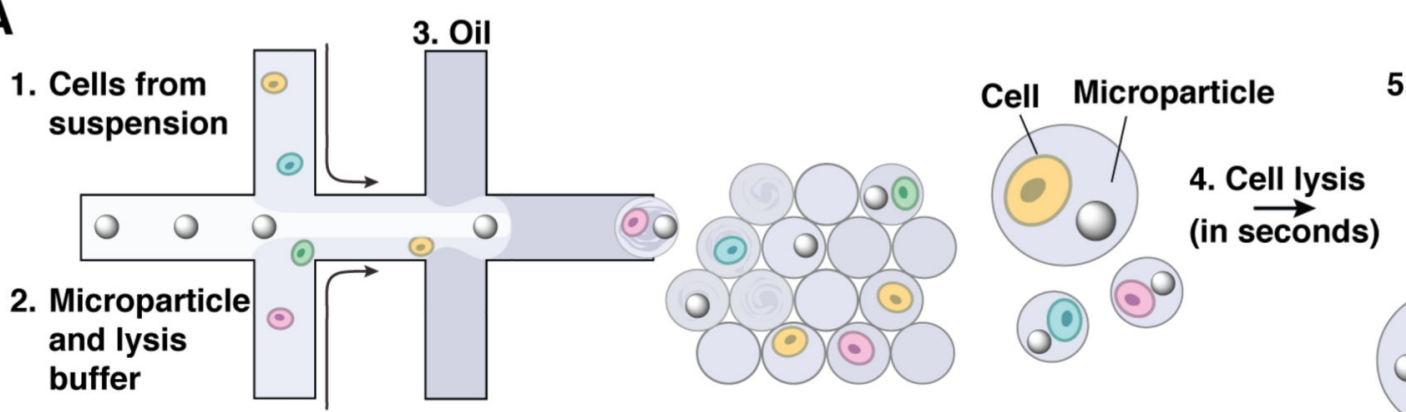

5. RNA hybridization

7. Reverse transcribe w/

6. Break droplets
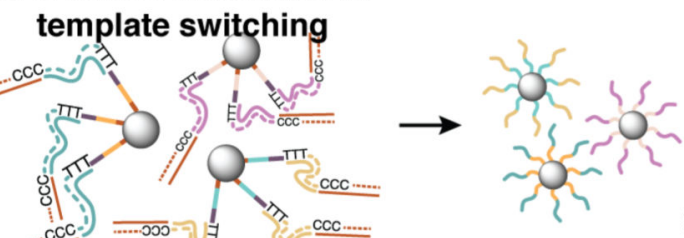

8. PCR

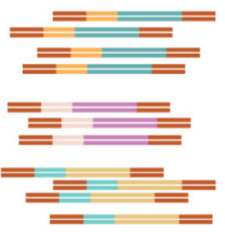

9. Sequencing

STAMPs as templates

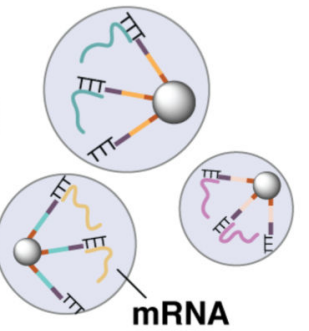

B
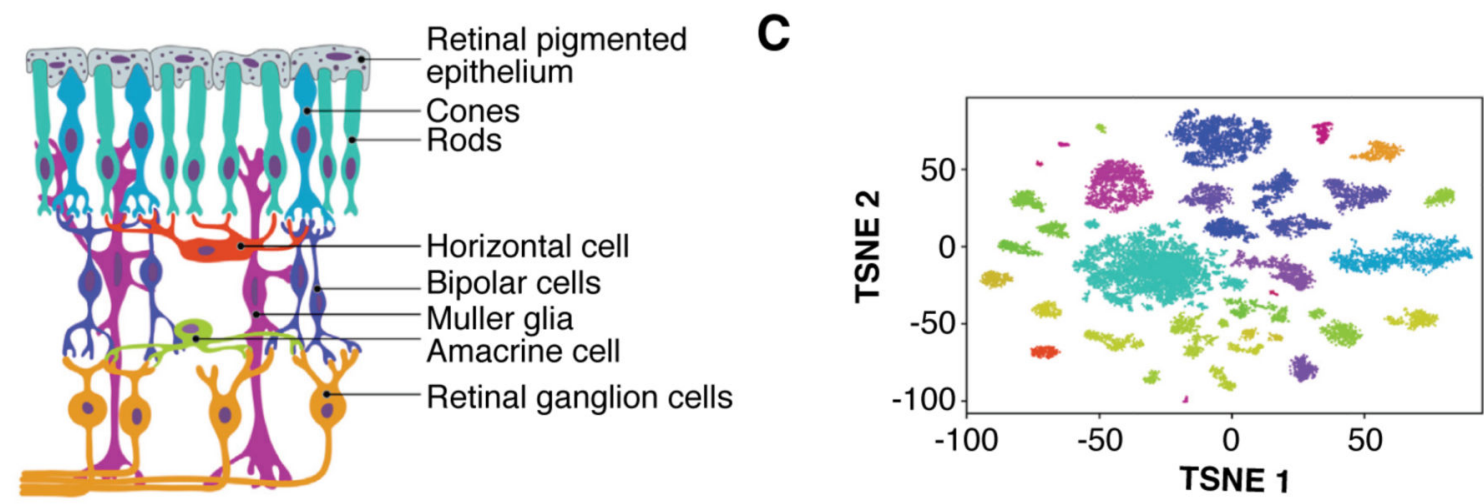

Figure 9.

Droplet-parallelized single-cell quantitative mRNA analysis. (A) The workflow begins with encapsulation of individually barcoded poly-dT-functionalized mRNA capture beads and cell suspension into droplets. In-droplet cell lysis and subsequent mRNA hybridization yields templates for reverse transcriptase to extend bead-bound DNA oligonucleotides. PCR amplification of the STAMPs (single-cell transcriptomes attached to microparticles) generates libraries for deep sequencing. (B) Retina tissue samples contain a variety of epithelial, sensor and neuronal cells types, which (C) cluster tightly according to transcriptional profile in a t-distributed stochastic neighbor embedding analysis. Some cell types exhibit multiple distinct transcriptional states. Reprinted from Cell, 161, Macosko, E. Z.; Basu, A.; Satija, R.; Nemesh, J.; Shekhar, K.; Goldman, M.; Tirosh, I.; Bialas, A. R.; Kamitaki, N.; Martersteck, E. M.; Trombetta, J. J.; Weitz, D. A.; Sanes, J. R.; Shalek, A. K.; Regev, A.; McCarroll, S. A., "Highly Parallel Genome-wide Expression Profiling of Individual Cells Using Nanoliter Droplets," 1202-1214, Copyright 2015, with permission from Elsevier. (ref 46) 
A

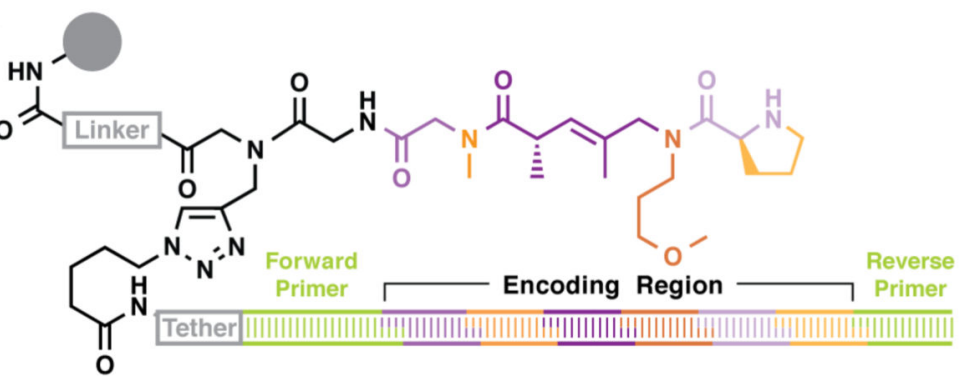

B
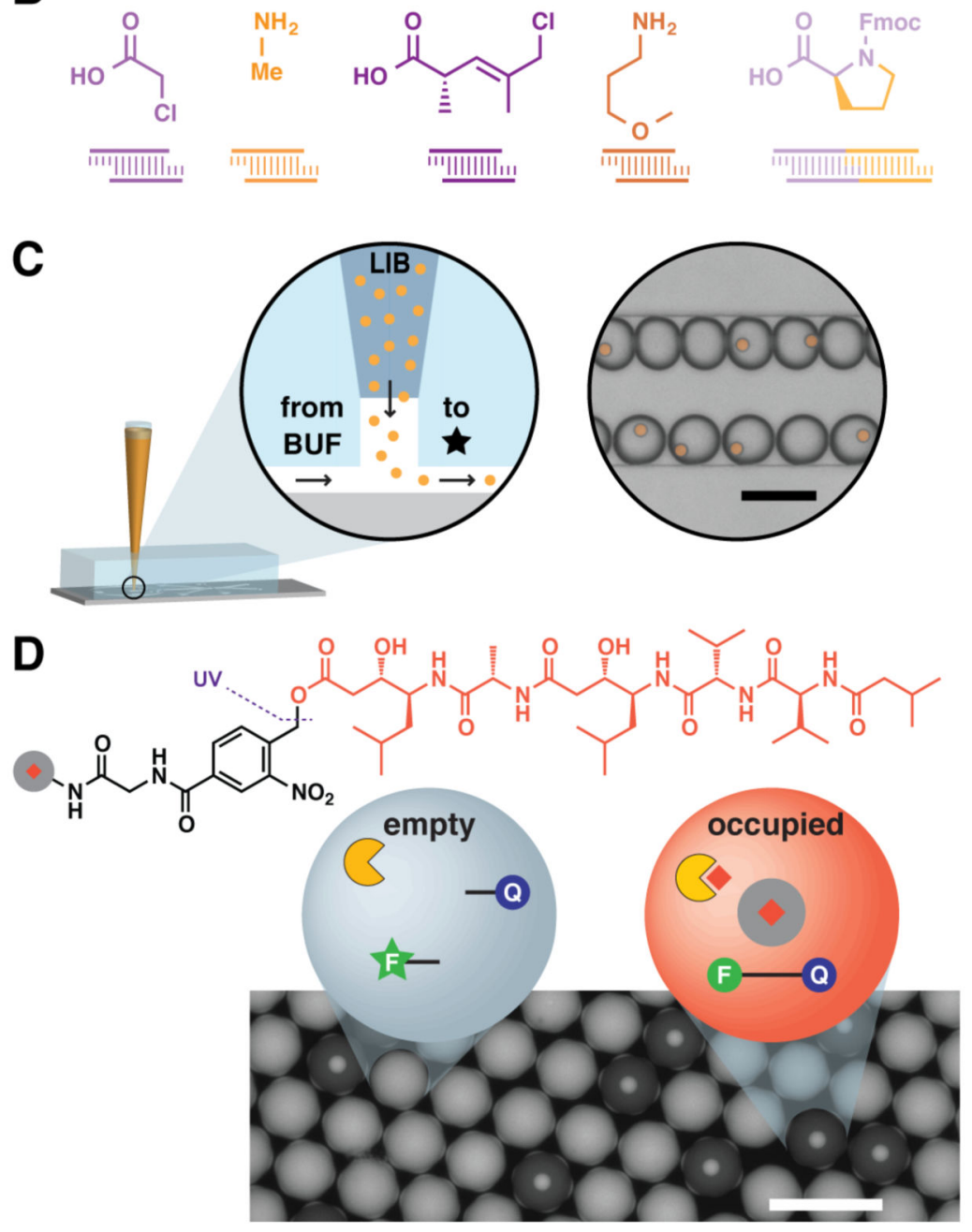

Figure 10.

A distributable droplet-scale small molecule discovery platform. (A) DNA-encoded solidphase synthesis can generate large and arbitrarily complex libraries, encoding each molecule's structure in a step-wise synthesized DNA tag. All tags feature common PCR primer binding sites for high-sensitivity detection. (B) Each sequence block in the tag correlates with a monomer added during synthesis. (C) Use of a suspension hopper enables large-format $(\sim 10 \mu \mathrm{m})$ bead loading. Particles settle out of a capped pipette tip into a microfluidic carrier flow and subsequent compartmentalization in droplets. (D) Pepstatin A, 
an aspartyl protease inhibitor, is attached to resin via a photolabile linker, loaded into droplets of a fluorogenic HIV-1 protease activity assay, and photolytically liberated into the assay. Liberated peptstatin inhibits proteolytic substrate cleavage and concomitant increase in fluorescence. Scale $=100 \mu \mathrm{m}$ Adapted with permission from MacConnell, A. B.;

McEnaney, P. J.; Cavett, V. J.; Paegel, B. M. ACS Comb. Sci. 2015, 17, 518-534 (ref 81). Copyright 2015 American Chemical Society. Adapted with permission from Price, A. K.; MacConnell, A. B.; Paegel, B. M. Anal. Chem. 2014, 86, 5039-5044 (ref 29). Copyright 2014 American Chemical Society. 